University of Wisconsin Milwaukee

UWM Digital Commons

Theses and Dissertations

May 2015

\title{
The Effect of E-Glass Fibers and Phlogopite Mica on the Mechanical Properties and Dimensional Stability of Rigid PVC Foams
}

Murtatha Jamel

University of Wisconsin-Milwaukee

Follow this and additional works at: https://dc.uwm.edu/etd

Part of the Engineering Commons

\section{Recommended Citation}

Jamel, Murtatha, "The Effect of E-Glass Fibers and Phlogopite Mica on the Mechanical Properties and Dimensional Stability of Rigid PVC Foams" (2015). Theses and Dissertations. 808.

https://dc.uwm.edu/etd/808

This Thesis is brought to you for free and open access by UWM Digital Commons. It has been accepted for inclusion in Theses and Dissertations by an authorized administrator of UWM Digital Commons. For more information, please contact open-access@uwm.edu. 


\title{
THE EFFECT OF E-GLASS FIBERS AND PHLOGOPITE MICA ON THE MECHANICAL PROPERTIES AND DIMENSIONAL STABILITY OF RIGID PVC FOAMS
}

by

Murtatha M. Jamel

\author{
A ThesisSubmitted in \\ Partial Fulfillment of the \\ Requirements for the Degree of \\ Master of Science \\ in Engineering
}

at

The University of Wisconsin-Milwaukee

May 2015 


\title{
ABSTRACT \\ THE EFFECT OF E-GLASS FIBERS AND PHLOGOPITE MICA ON THE MECHANICAL PROPERTIES AND DIMENSIONAL STABILITY OF RIGID PVC FOAMS
}

\author{
by \\ Murtatha M. Jamel \\ The University of Wisconsin-Milwaukee, 2015 \\ Under the Supervision of Professor Nidal Abu-Zahra
}

Short E-Glass Fibers (GF) and Phlogopite Mica (M) were used separately and simultaneously to enhance the dimensional stability and mechanical properties of extruded rigid Polyvinyl Chloride (PVC) foams. The reinforcing phases were added to rigid PVC compounds at different concentrations and processed using a single screw profile extruder. PVC foam composites were characterized for their dimensional stability, structural, thermal, and mechanical properties. In the first part of this work, two types of short E-glass fibers having different lengths (1/16" and 1/32") were added into rigid PVC foams at different concentrations (0-20 wt.\%). Experimental results of PVC foam-Glass Fibers composites (PVC-GF) show that the dimensional stability and storage modulus were enhanced for both fibers length $1 / 32$ " and $1 / 16$ "by $60 \%$ and $65 \%$ and $150 \%$ and $200 \%$, respectively, and enhancing the heat resistance as well. These improvements were obtained without compromising the tensile and flexural strengths of the composites. Overall, 
PVC foam-GF composites which were prepared with longer glass fibers exhibit better mechanical and thermal properties than those prepared with shorter glass fibers due to higher interlocking between the fibers and the foam cells, which result in better load distribution in the matrix.

In the second part of this work, high aspect ratio Phlogopite mica was added to rigid PVC compounds at different concentrations (0-20 wt. \%). Experimental results of PVC foam-Mica composites show that the dimensional stability and storage modulus were enhanced by $44 \%$ and $113 \%$, respectively, and heat resistance and tensile strength of the composites were also enhanced with the addition of mica. However, increasing the concentration of mica had no significant effect on the impact and flexural strengths of the composites. SEM micrographs show good dispersion and orientation of mica flakes along the cell walls of the PVC foam. Overall, the platy structure and physical properties of mica seemed to have played an important role in providing good interfacial bonding with the cell membranes of the foam, thus enhancing the dimensional stability of the PVC-Mica foam composites.

Finally, short E-glass fibers (1/16") and Phlogopite mica were added as a combination (GM) to rigid PVC compounds at different concentrations. Experimental results of PVC foam-Glass Fibers and Mica composites (PVC-GM) show that the dimensional stability increased by $50 \%$ and heat resistance of the samples improved as the amount of reinforcing solids increased in the composites 
at high glass fibers to mica ratio. The storage modulus, tensile, and flexural strengths of the composites were improved by $220 \%$, $82 \%$, and $46 \%$, respectively. However, the impact strength and the ductility decreased. SEM micrographs show the bonding between glass fiber through the foam cells and a good dispersion and orientation of the mica flakes along the cell walls of the PVC foam. 
(C) Copyright by Murtatha M. Jamel, 2015 All Rights Reserved 
Dedicated to My

Ofamily

Grandfather@Grandmother

Qlucle

Drunts 


\section{TABLE OF CONTENTS}

CHAPTER

PAGE

Abstract

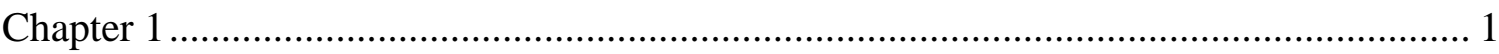

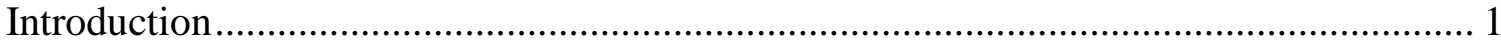

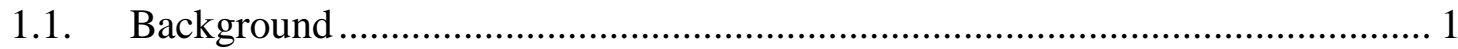

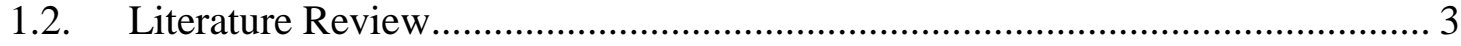

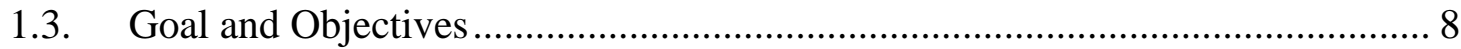

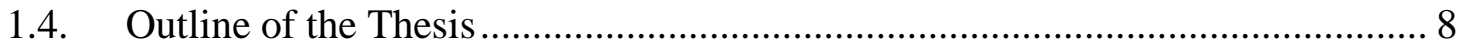

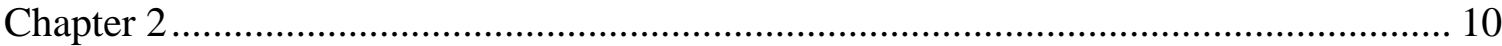

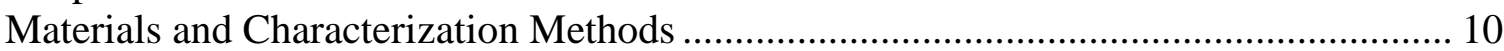

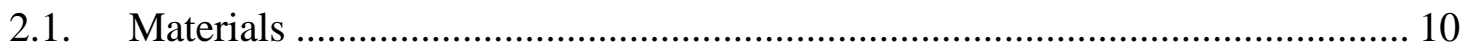

2.1.1. PVC foam compound................................................................ 10

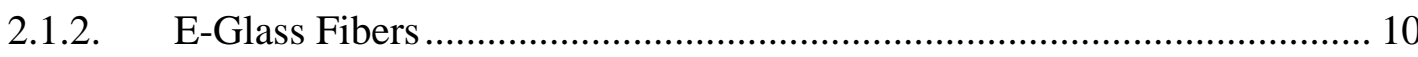

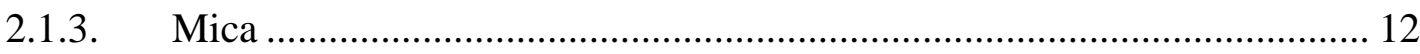

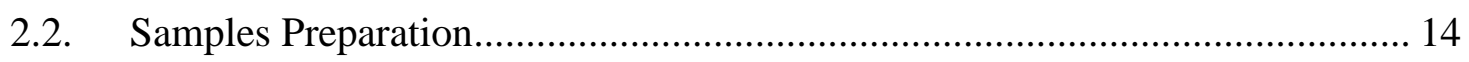

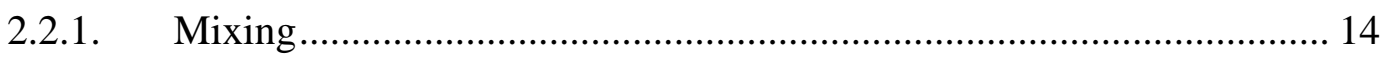

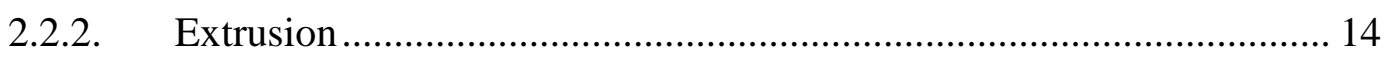

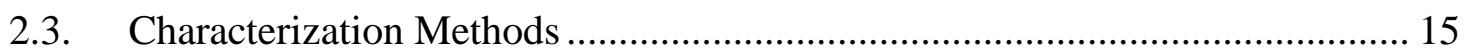

2.3.1. Thermal Characterization............................................................ 15

2.3.1.1. Thermo-Gravimetric Analysis (TGA)..................................... 15

2.3.1.2. Differential Scanning Calorimetry (DSC)................................ 16

2.3.1.3. Dynamic Mechanical Analysis (DMA)..................................... 16

2.3.1.4. Dimensional Stability ............................................................ 16

2.3.2. Mechanical Properties.............................................................. 17 
3.1.2.1. Tensile Testing ..................................................................... 17

3.1.2.2. Compressive Testing............................................................. 17

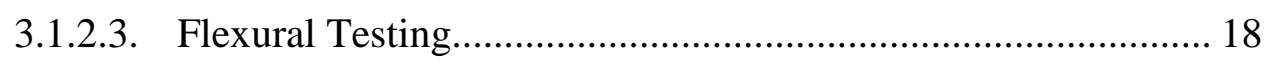

3.1.2.4. Impact Testing....................................................................... 18

2.3.3. Scanning Electron Microscopy ……………………………….......... 19

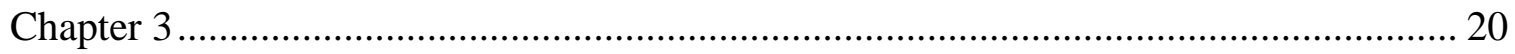

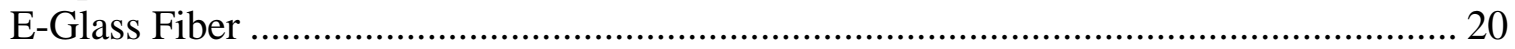

3.1. PVC-GF Foam Composites Formulation........................................................ 20

3.2. Results and Discussion ............................................................................ 21

.3.2.1 Thermal Properties................................................................................ 21

3.2.2. Mechanical Properties....................................................................... 30

3.2.3. Microstructural Morphology ................................................................... 32

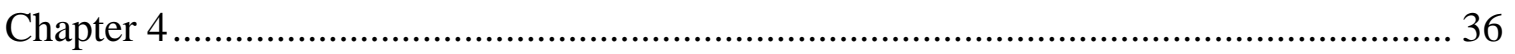

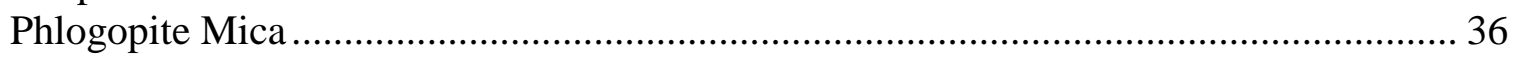

4.1. PVC-Mica Foam Composites Formulation ………………………………...... 36

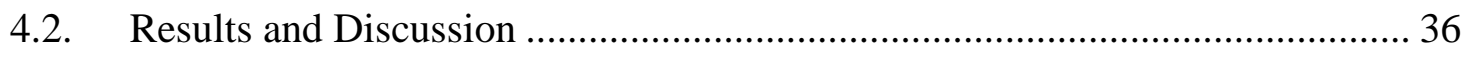

.5.1.3 Thermal Properties................................................................................. 36

5.1.4. Mechanical Properties........................................................................... 43

5.1.5. Microstructural Properties ........................................................................ 47

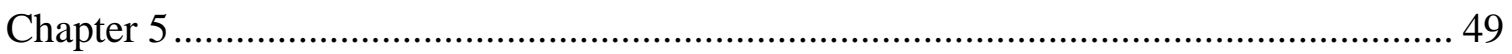

A combination of E-Glass Fibers and Phlogopite Mica .................................................... 49

.5.1 PVC-GM Foam Composites Cormulation.......................................................... 49

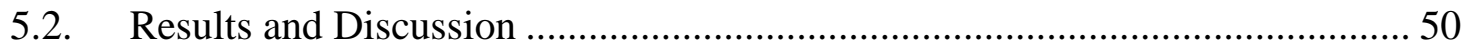

.5.2.1 Thermal Properties................................................................................ 50

5.2.2. Mechanical Properties.......................................................................... 57

5.2.3. Microstructural Properties .......................................................................... 61

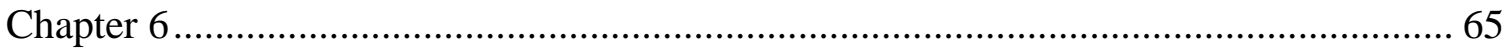

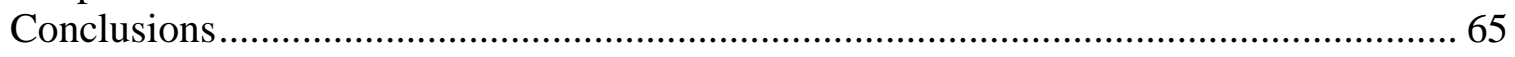

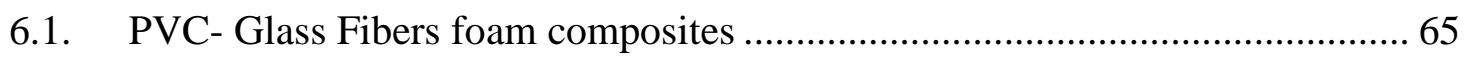

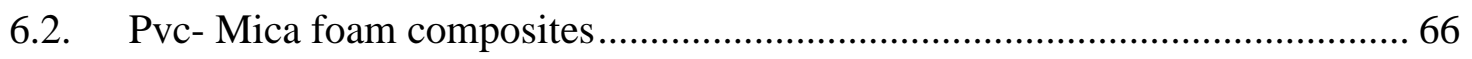




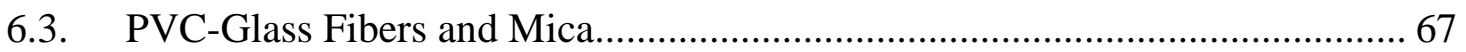



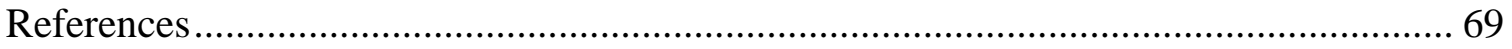

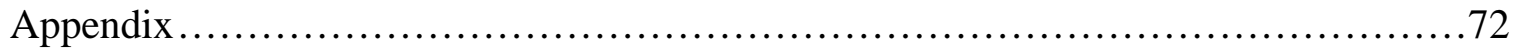




\section{LIST OF FIGURES}

FIGURE

PAGE

Figure 1: SEM micrograph of short glass fibers as received.(a) 1/16"at $50 \mathrm{X}$ (b) $1 / 32$ " at $50 \mathrm{X}$ (c) GF at 500X

Figure 2: SEM micrograph of mica platelets as received at $1000 \mathrm{x}$ 13

Figure 3: Dimensional stability of PVC-GF foam composites 22

Figure 4: Distortion in PVC-GF foam composites before and after .... 23

Figure 5: TGA analysis of PVC-GF foam composites (a) 1/16" (b) 1/32". 25

Figure 6: Storage Modulus (E') of PVC-GF foam composites (a) 1/16", (b) 1/32". ...... 28

Figure 7:Loss Modulus (E") of PVC-GF foam composites (a) 1/16" (b) 1/32". 29

Figure 8:SEM micrographs at 50x of 1/16" PVC-GF foam composites: (a) 5\% (b) 10\% (c) $15 \%$ (d) $20 \%$ 33

Figure 9: SEM micrographs at 150x of 1/32" PVC-GF foam: (a) 5\% (b) 10\% (c) 15\% (d) $20 \%$ 34

Figure 10: SEM micrograph at 1000x of a glass fiber interface with PVC foam 35

Figure 11: Dimensional stability of PVC-Mica foam composites 38

Figure 12: Distortion in PVC-Micafoam composites before and after heat treatment. ... 38

Figure 13: TGA analysis of PVC-Mica foam composites, the curves are labeled with respect to the value of residual weight at $800{ }^{\circ} \mathrm{C}$ from the top to bottom.

Figure 14: Storage Modulus (E') of PVC-Mica foam composites 42 
Figure 15: Loss Modulus (E") of PVC-Mica foam composites.

Figure 16: Ultimate Tensile Strength (UTS) of PVC-Mica foam composites. 44

Figure 17: Ductility of PVC-Mica foam composites 45

Figure 18: SEM micrographs of PVC-Mica foam composites at: (a) $0 \%$ (b) $5 \%$ (c) $10 \%$

(d) $15 \%$ and (e) $20 \%$ mica 48

Figure 19: Dimensional stability of PVC-GM foam composites 51

Figure 20:Distortion in PVC-GM foam composites before and after heat treatment...... 52

Figure 21: TGA analysis of PVC-GM foam composites, the curves are labeled with respect to the value of residual weight at $800^{\circ} \mathrm{C}$ from the top to bottom......................... 54

Figure 22: Storage Modulus (E') of PVC-GM foam composites................................. 56

Figure 23:Loss Modulus (E") of PVC-GM foam composites .................................... 57

Figure 24: Ultimate Tensile Strength (UTS) of PVC-GM foam composites .................. 58

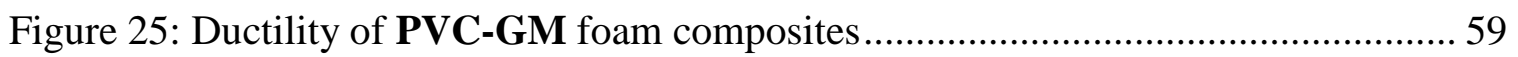

Figure 26: SEM micrographs of PVC-GM foam composites: (a) G0M0 at 150x (b) G5M5 at 300x(c) G10M10 at 500x (d) G5M15 at 500x (e) G15M5 at 150x (f) G 15M5 at

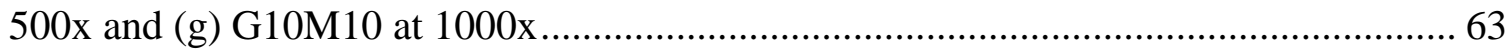




\section{LIST OF TABLES}

TABLE

PAGE

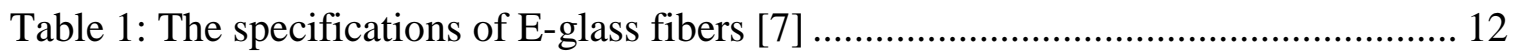

Table 2: Particle size distribution of Phlogopite Mica PW80 [6] ................................... 13

Table 3: Chemical analysis of Phlogopite Mica PW80 [6]........................................... 13

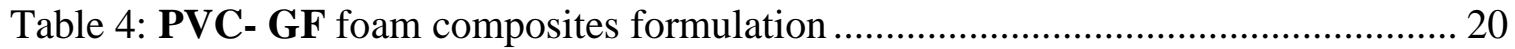

Table 5: Glass transition temperatures of the PVC-GF foam composites measured by

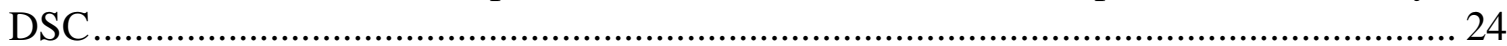

Table 6: Primary and Secondary Decomposition Temperature of PVC-GF foam

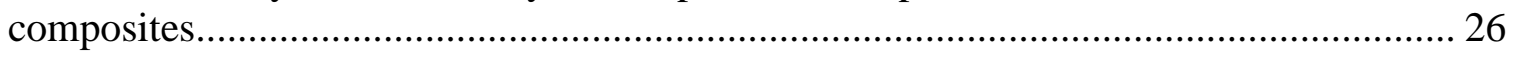

Table 7: Mechanical properties of PVC-GF foam composites .................................... 31

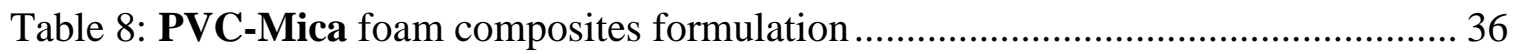

Table 9: Glass transition temperatures of PVC-Mica foam composites determined by

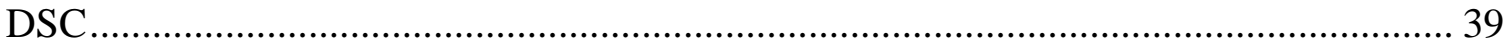

Table 10: Primary and Secondary Decomposition Temperature of PVC-Mica foam

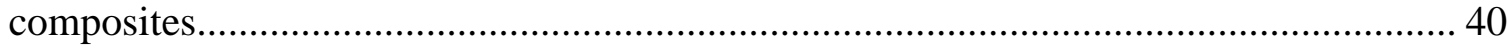

Table 11: Mechanical properties of PVC-Mica foam composites ................................ 46

Table 12: Composition of PVC-Glass Fiber and Mica (GM) foam composites .......... 49

Table 13: Glass transition temperatures of PVC-GM foam composites determined by




Table 14: Primary and Secondary Decomposition Temperature of PVC-GM foam

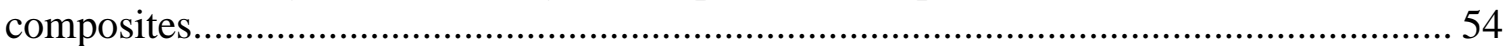

Table 15: Mechanical properties of PVC-GM foam composites....................................... 61 


\section{LIST OF EQUATIONS}

EQUATION

$\%$ Shrinkage $=\frac{l_{0}-l_{f}}{l_{0}} \times 100$

$\sigma_{\mathrm{f}}=\frac{3 \mathrm{PL}}{2 \mathrm{bd}^{2}}$

$\varepsilon_{\mathrm{f}}=\frac{6 \mathrm{Dd}}{\mathrm{L}^{2}}$
PAGE

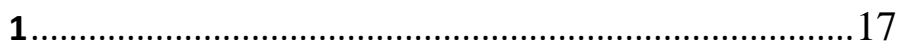

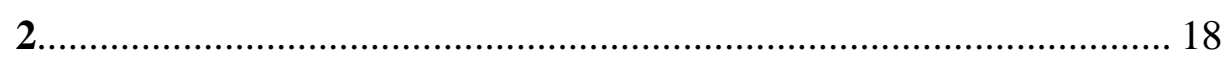

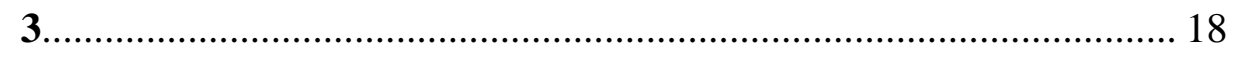




\section{ACKNOWLEDGEMENTS}

I would like to use this opportunity to express my appreciation to everyone that has assisted me throughout my master's degree. I am grateful to Professor Nidal Abu-Zahra for his continuous support and invaluable advice since the beginning of my research. It has been an absolute pleasure to work with him, thanks again for the tremendous assistance and guidance that he provided me during my study.

I would also like to thank committee members Professor Benjamin Church and Professor Habib Tabatabai for their time and priceless comments and suggestions whichadd more potential to my thesis. I am grateful to them for sharing their valued knowledge and views with me to finalize this thesis.I would like to express my appreciation to Dr. Steven Hardcastle, who introduced and trained me on using advanced characterization techniques in Advanced Analyses Facility at UW-Milwaukee.Moreover, I am thankful to Jenna Jazna and Jonathan Bruce who helped me in revising the format of this work.

In addition, I am grateful to Hamanajih Hawramy and his wife, as well as Professor Lewis Tusken and his wife Sally, for their encouragement and support. My thanks also goes to Diler Zangana and Erin Fox for helping me with theapplication process to this master's program. Also, my gratitude to Gossen Company for letting me use their facilities and equipment, I am also thankful to Dr. 
Cem Gogtas who trained me on manufacturing equipment at the company. A special thanks to everyone who works on developing and supporting the diverse fields of science to serve human beings. 


\section{CHAPTER 1}

\section{INTRODUCTION}

\subsection{BACKGROUND}

Polymer foams are a unique class of materials that are widely used due to their light weight, low cost, and good formability along with load bearing and insulation capabilities. The cellular structure of the foam determines its mechanical and physical properties, and hence its performance and applications [1, 2]. Rigid Polyvinyl Chloride (PVC) foams and their composites have been used as an excellent replacement for wood in the building materials industry in the form of profiles, sheets, and pipes due to their low cost, low density, fire retardancy, and high insulation and damping properties. However, rigid PVC foams lack adequate dimensional stability when they are exposed to high and low temperatures. Certain applications of PVC foam products require excellent dimensional stability, such as in exterior moldings, siding, decking and railing applications. Solid fillers, such as calcium carbonate, talc, glass fibers, carbon fibers, and wood fibers, have been reported as effective PVC reinforcement additives in many publications [3-5]. The selection process of an effective reinforcement filler depends on its compatibility with the polymer matrix and the desired relationship between structure, property, and performance for the composite. 
Mica is a general term applied to a group of complex aluminosilicates containing potassium, magnesium, iron, sodium, fluorine and/or lithium. Each member of the group exhibits different physical properties but all form flat six sided monoclinical crystals with a definite cleavage in the direction of large surfaces, allowing them to split easily into optically flat films as thin as $1 \mu \mathrm{m}$. According to the chemical composition and the physical properties of these silicates, mica can be classified into several types. Phlogopite and Muscovite are the most known types of mica used industrially, and each one has distinguished features. Phlogopite mica can be recognized by high concentrations of magnesium, a bronze-gold color, and opaquenessto UV, while Muscovite mica contains high levels of aluminum and is white in color and transparent to UV. Phlogopite mica, a hydrated silicate of potassium and magnesium is associated with metamorphosed limestone and ultrabasic rocks, particularly hydrothermal veins formed through metasomatism of magnesium-rich rocks as well as ultrabasic and carbonatite ring intrusions associated with ancient shield areas [6].

Micas are characterized by a sheet or plate like structure, which because of its excellent basal cleavage of these very thin platelets with high surface area-tovolume enables particles of high aspect ratio to be produced. These lamellar particles are flexible, tough, relatively soft, have a low coefficient of thermal expansion, exceptional electrical properties and excellent chemical resistance.The high aspect ratio platy particles provide an excellent balance of mechanical, thermal and dimensional properties when used as functional filler in plastics providing 
increased stiffness, high temperature performance, improved scratch resistance, acoustic damping properties, lower Coefficient of Linear Thermal Expansion (CLTE) and improved dimensional stability [6].

E-Glass fiber contains oxides of silicon, calcium, aluminum, magnesium, and boron fused in an amorphous hyaline phase. This glass fiber is alkali free and made with a virgin glass which produces a uniform diameter that leads to consistent properties between the fibers which can be reflected on the performance of composite materials. E-Glass fibers are widely used as reinforcements in polymer matrix composites due to their ability to improve certain mechanical properties, dimensional stability, thermal properties, as well as structural properties [7]. It has been reported elsewhere that glass fibers improve dimensional stability and mechanical strength in PVC composites [8, 9]. Different lengths of glass fiber have been used to reinforce polymer composites; using long fibers led to better improvement in properties. Although short glass fibers are known to yield lower enhancement in their composites when compared to their longer counterparts, they are still widely used in polymer composites due to their processing advantages [10].

\subsection{LITERATURE REVIEW}

Based on our literature review, there is very limited work on the effect of mica and/or glass fiber on the dimensional stability and mechanical properties of polymer foams. Otherwise, the use of mica as a reinforcement filler in non-foam polymer composites has been studied and reported extensively. Liang et al. [11] 
studied the effect of mica on the mechanical and thermal properties of high density polyethylene (HDPE) at different mica contents (5\%, 10\%, and 15\%). They reported improvements in the tensile and yield strengths and deterioration in the impact strength of the composites. Souza et al. [12] studied the thermal properties of mica filled poly(lactic acid) composites at different concentrations of mica (2.5\%, 5\%, and $7.5 \%)$; it was reported that the thermal stability was improved by increasing the mica's content. M. Sreekanth et al. [13] worked on reinforcing extruded Polyester composites with mica (0-40 wt. \%). The rigidity and thermal properties of the extruded samples were enhanced by adding mica; whereas the impact strength deteriorated at higher mica contents. Similarly, Marshall et al. [14] reported an increase in the tensile modulus of PP, HDPE, and PVC composites with the addition of mica while maintaining the original levels of tensile strength. S. Deshmukh et al. [15] examined the effect of different parameters, such as particle size, concentration, and surface treatment, on the mechanical properties of reinforced PVC-Mica composites (non-foam). They reported poor dispersion at high contents of mica which led to phase separation of the mica agglomerates in the polymer matrix.

Jang et al. [16] studied GF reinforced preparedpoly(butylene terephthalate) (PBT) composites using an extrusion process. They reported enhancement in mechanical properties only when using sufficient coupling agents in order to improve the interfacial bonding between glass fibers and the polymer matrix. They also claimed that the loading amount and length of glass fibers, as well as the 
extrusion conditions determine the final mechanical properties of PBT-GF composites. Hassan et al. [17] prepared PP reinforced glass fibers using Maleic Anhydride polypropylene (MAPP) as a coupling agent in extrusion and injection molding. They reported modest change in the melting temperature of the composites with increasing GF and MAPP contents. Dynamic mechanical analysis (DMA) showed an improvement in the viscoelastic properties of the composite with low GF loadings in the presence of the coupling agent. Ozkoc et al. [18] studied the effect of content (10\%-30\% GF) and extrusion conditions of surface treated short GF on the mechanical properties of acrylonitrile-butadiene-styrene (ABS). In their work, polyamide-6 (PA6) was used at different levels to improve the bonding between GF and the matrix. They reported that the tensile strength, tensile modulus, flexural modulus, and impact strength of the composites are lower when using shorter glass fibers. However, mechanical properties improved slightly when using higher amounts of short GF and PA6. Thomason et al. [19] studied the effect of the length, diameter $(10,14,17 \mu \mathrm{m})$, and content $(10 \%-50 \%)$ of GF on the impact properties of polyamide 6,6 reinforced with GF using notched and unnotched impact samples. They reported that the impact properties of the notched samples were more sensitive to the fiber length and content, while the fiber diameter and content were the main parameters affecting the impact strength of the un-notched samples. Jiang [20] studied the influence of short (0.8 mm) and long (6.4 mm) glass fibers on the impact strength of PVC/wood flour/glass fibers at a constant loading level of 5\% for short glass fibers and (2, 5, 10, and 20\%) of long glass fibers. It was reported that the long glass fiber improved the impact strength 
by $36 \%$ to $100 \%$ at $20 \%$ content of long glass fiber, while maintaining flexural properties, whereas the short glass fiber did not show any significant improvements. Deaninet al. [21] investigated the effect of adding different loading levels (10, 20, and 30\%) of short GF on the dimensional stability of Poly(butylene terephthalate) foam composites. They reported enhancement in the dimensional stability when using coupling agents and surface treatments to enhance the bonding between the glass fibers and polymer matrix. Tungjitpornkull et al. [22] prepared E-chopped glass fiber filled wood/PVC composites at different GF loadings, 10, 20 and $30 \mathrm{phr}$, with various fiber lengths (3, 6 and $12 \mathrm{~mm}$ ). They concluded that the most critical parameter in determining the shrinkage, the tensile, and the flexural properties of the composites is glass fiber loading in the composite. Besides that, it was found the tensile and the flexural properties of the composites were more influenced by the interfacial bonding between glass fibers and the matrix at 10 and $20 \mathrm{phr}$. On the other hand, GF with $6 \mathrm{~mm}$ length showed better improvement than 3 or $12 \mathrm{~mm}$ at 10,20 , and $30 \mathrm{phr}$ of GF. While the effect of GF length was insignificant on the reduction in shrinkage, the shrinkage was reduced by $76 \%$ at 30 phr of GF.

Zhao et al. [23] studied the use of $0-50 \%$ mica on the mechanical properties of polypropylene-based GMT composites, they reported improvement in the tensile and flexural strengths of the composites at lower mica content (10\%). The same properties were compromised at higher mica contents (e.g., 20-50\%). The impact strength was maximized at $20 \mathrm{wt} \%$ mica content. Raj et al. [24] studied the effect 
of heat exposure on the mechanical and thermal properties of glass fiber, mica and wood fiber reinforced low density polyethylene (LDPE) individually at different concentrations $(0,10,20,30,40 \%)$; they reported that the composites glass fibers and mica reinforced LDPE show better dimensional stability than wood fiber. On the other hand, the tensile modulus was increased by increasing the fillers content, where the mica composites recorded the highest tensile modulus.The glass fiber composites that were not subjected to any aging recorded the highest tensile strength at $10 \%$ and $20 \%$ glass fiber. Canova et al. [25] examined the use of glass fibers and mica in Polypropylene (PP) composites; they used 20-40\% of total filler content as a combination of glass fibers and mica. The dimensional stability was reported to improve by adding glass fiber and mica; the linear shrinkage based on $49^{\circ} \mathrm{C}$ was measured to be $0.6 \%$ at $40 \%$-Glass Fiber compared to $1.01 \%$ at $20 \%$ Glass Fiber. It was measured to be $0.64 \%$ at $40 \%$ of mica compared to $1.6 \%$ at $20 \%$ of mica. In addition to that, the total filer (glass fiber and mica) led to decrease the shrinkage as well; more decrement occurred when the ratio of glass fiber to mica had increased. On the other hand, the flexural strength increased by increasing both mica and glass fiber content. The tensile strength reached the highest value by using maximum content of glass fiber and minimum content of mica. Jiang et al. [26] reviewed the effect of adding mica and glass fibers to PVC-Wood foam composites using chemical blowing agents. They cited improvement in the mechanical properties of the foam composites by adding mica or glass fibers. 


\subsection{GOAL AND OBJECTIVES}

The goal of our work is to enhance the mechanical and physical properties of extruded rigid PVC foam using a combination of short glass fibers and Phlogopite mica. The goal is achieved by attaining the following objectives:

1. Study the effect of short glass fibers and mica, separately and combined, on the mechanical, physical, and structural properties of the rigid foam composites.

2. Study the microscopic bondings between the filler particles and the polymer matrix using SEM analysis

3. Study the relationship between the structural changes in the presence of filler particles and the performance of the foam composites under a wide range of loading conditions.

\subsection{OUTLINE OF THE THESIS}

The background of PVC foams and the motivation of this thesis have been mentioned in the first chapter. In addition, the literature review on using E-glass fiber and mica to reinforce various kinds of polymers was covered. Thematerials, samples preparation, and characterization methods of the foam composites will be explained in the second chapter, where the samples were subjected to different tests: tensile test, flexural test, shrinkage test, Dynamic Mechanical Analysis 
(DMA), Differential Scanning Calorimetry (DSC), and Thermal Gravimetric Analysis (TGA). Besides that, Scanning Electron Microscopy (SEM) was used for microstructural investigation.

The effect of adding E-glass fibers (GF) on the properties of PVC foams at different concentrations, besides the influence of each fiber length on the performance of the foam composites, will be discussed in chapter 3 , and the effect of reinforcing PVC foam composites with mica and characterization of this phase will be described in chapter 4 . The last reinforcing phase of glass fibers and mica as a combination will be explained in chapter 5.The conclusion will be collected in chapter 6. 


\section{CHAPTER 2}

\section{MATERIALS AND CHARACTERIZATION METHODS}

\subsection{MATERIALS}

\subsubsection{PVC FOAM COMPOUND}

Rigid PVC resin was purchased from Shintech, USA; it has an inherent viscosity of 0.74 (ASTM D1243), bulk density of $36.3 \mathrm{lb} / \mathrm{ft} 3$ (ASTM D 1895), and maximum volatiles of $0.12 \%$ (ASTM D3030). A commercially available thermal stabilizer, Thermolite T-137, and processing aids, Plastistrength P530 and P770, were provided by Arkema, USA. Other ingredients used in preparing the samples are Lubricants Loxiol 2986 and 2987, produced by Oleochemicals, paraffin wax Petrac 215 produced by Ferro Corp., Calcium Stearate COAD 10 produced by Norac Corp., chemical blowing agents Azodicarbonamide (ADC) produced by Season Corp., and Sodium Hydrogen Carbonate (FICEL SBH) produced by Hughes Polymer Additives Corporation. The specific content of each ingredient is considered proprietary; however, the amount of each ingredient follows a common formulation used in making rigid PVC foams.

\subsubsection{E-GLASS FIBERS}

Milled and saline treated E-glass fibers, with two lengths of 1/16" and 1/32" with diameter of 16 microns, were used as received from Fiber Glast Developments Corporation, USA. The SEM micrographs of the glass fibers are shown in Figure 1. 
From these micrographs, it can be observed that the glass fibers of $1 / 32$ " showa significant number of fibers with a length less than 200 microns. The dimensionand the supplier specifications of the fibers are shown in Table 1.
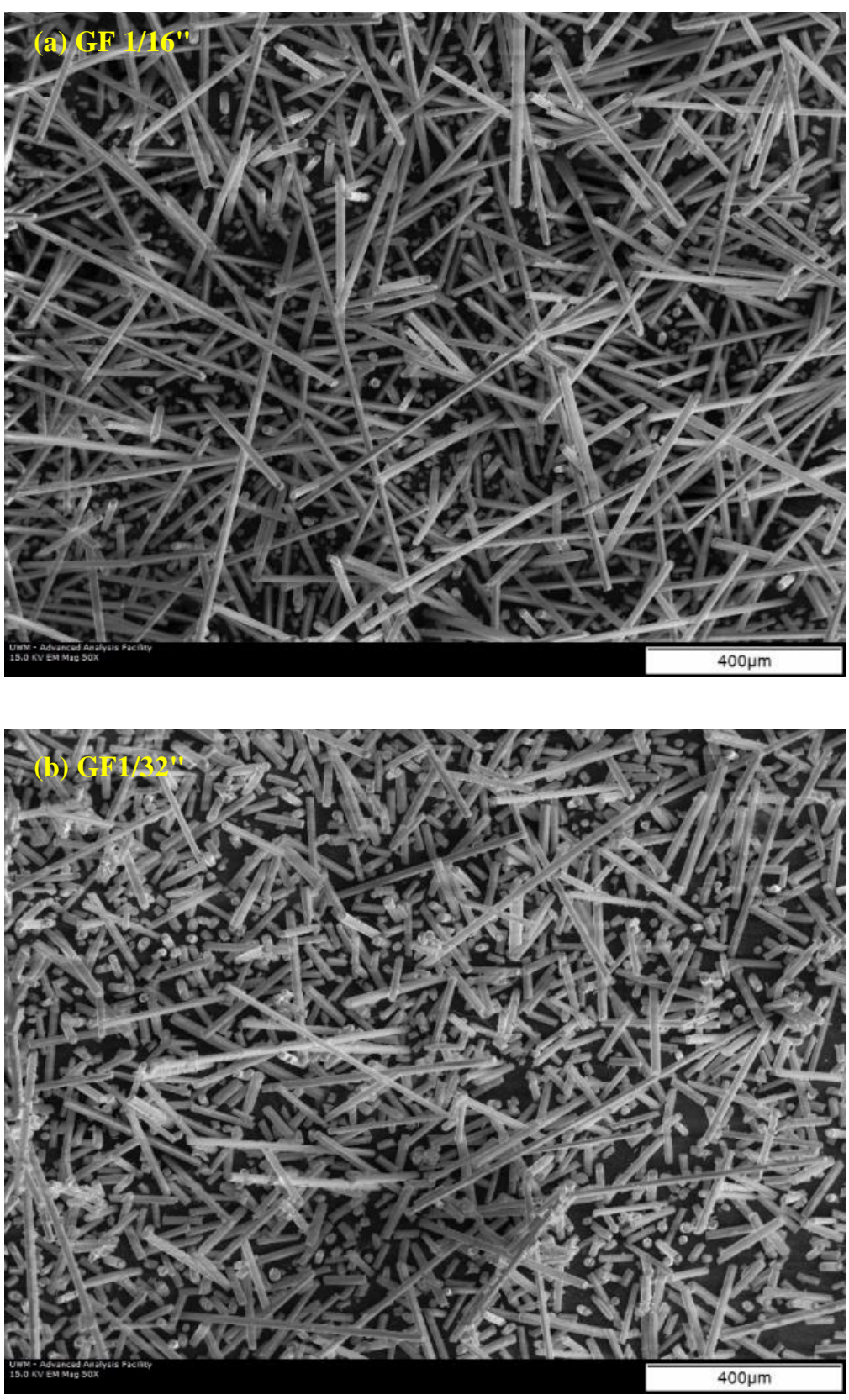


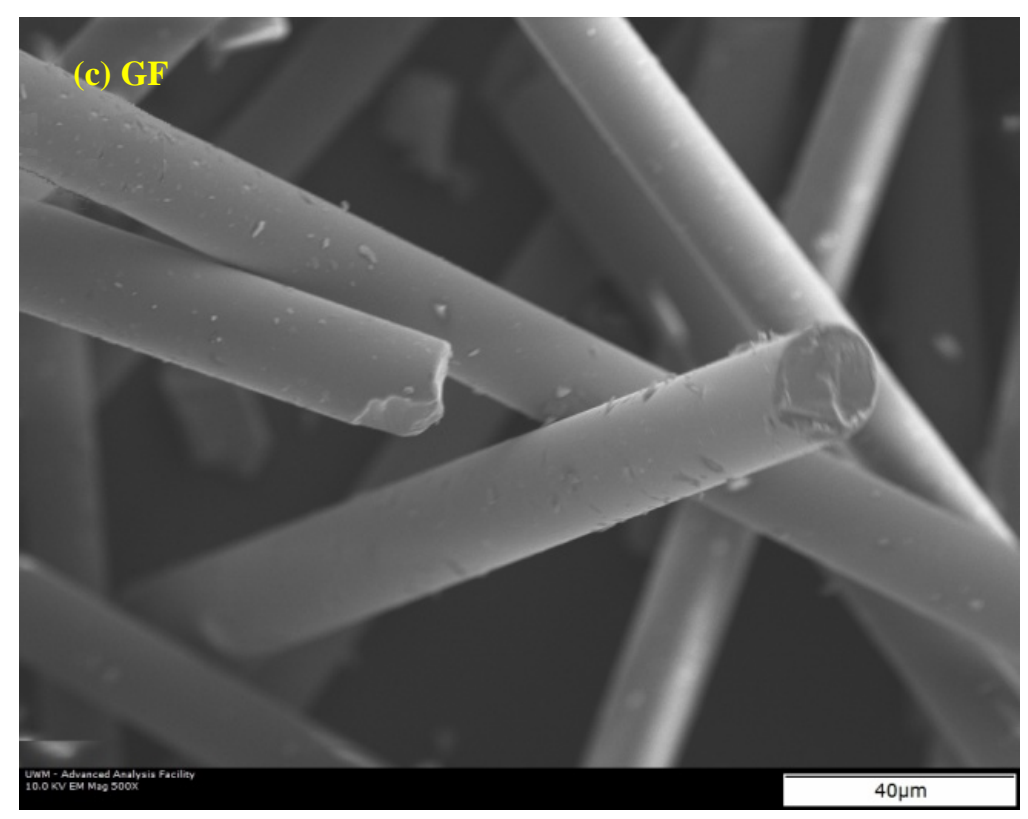

Figure 1: SEM micrograph of short glass fibers as received.(a) 1/16"at 50X (b) 1/32" at $50 X(c)$ GF at $500 X$

Table 1: The specifications of E-glass fibers [7]

\begin{tabular}{|c|c|}
\hline Specifications & Average Value \\
\hline Fiber Diameter & 16 microns \\
\hline Bulk Density & 0.30 for $(1 / 16 ")$ and $0.53 f o r(1 / 32 ") \mathrm{g} / \mathrm{cc}$ \\
\hline Moisture Content & $<0.1 \%$ \\
\hline Loss of Ignition & $<0.08 \%$ \\
\hline Contamination & $\begin{array}{c}\text { Free of foreign matter, dirt, oil or grease, and hard } \\
\text { lumps of modulated and /or unmilled fibers. }\end{array}$ \\
\hline Sizing & Silane \\
\hline Appearance & Floccular \\
\hline
\end{tabular}

\subsubsection{MICA}

Figure 2 shows the platy structure of mica. The particle size distribution and chemical analysis of PW80 Phlogopite mica, with an aspect ratio of more than 100:1, are shown in Table 2 and Table 3, respectively. 


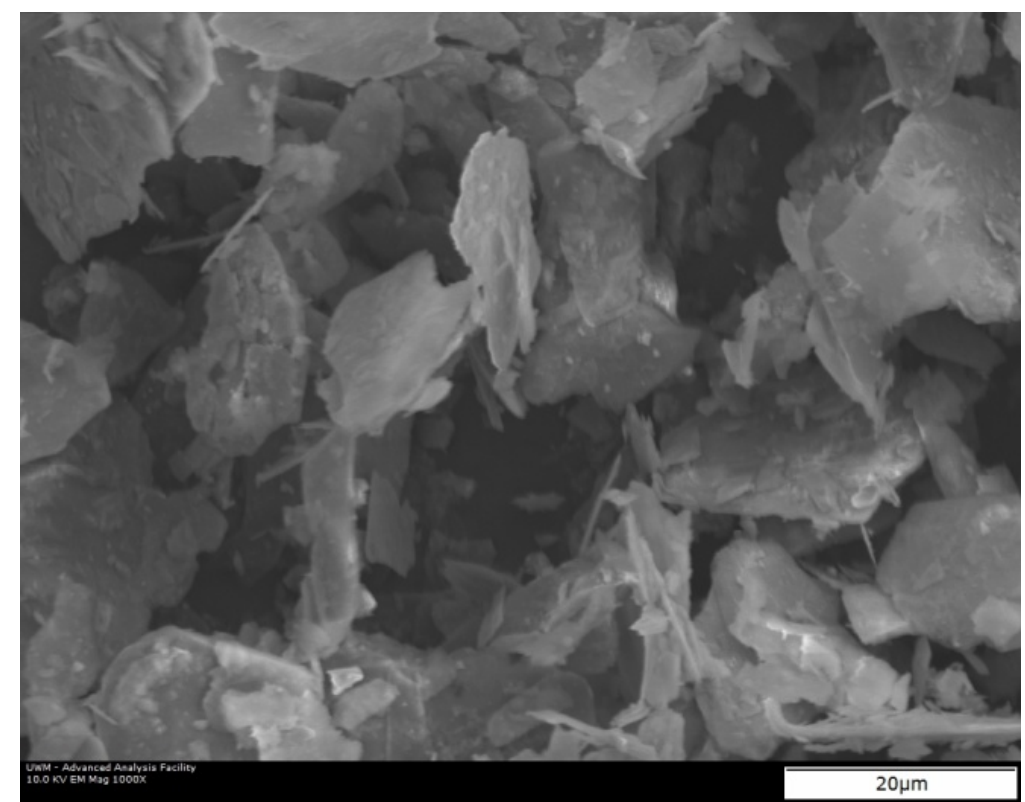

Figure 2: SEM micrograph of mica platelets as received at 1000x

Table 2: Particle size distribution of Phlogopite Mica PW80 [6]

\begin{tabular}{|c|c|c|}
\hline BS Mesh No. & Sieve Aperture (Microns) & Cumulative \% Passing \\
\hline 60 & 250 & $99.9-100$ \\
\hline 100 & 150 & $96-100$ \\
\hline 350 & 45 & $70-95$ \\
\hline \multicolumn{2}{|c|}{ Loose Bulk Density } & $0.15-0.35 \mathrm{~kg} / \mathrm{liter}$ \\
\hline
\end{tabular}

Table 3: Chemical analysis of Phlogopite Mica PW80 [6]

\begin{tabular}{|c|c|}
\hline Chemical Analysis & \% by weight \\
\hline Silicon as $\mathrm{SiO}_{2}$ & $40-42$ \\
\hline Magnesium as $\mathrm{MgO}$ & $20-26$ \\
\hline Potassium as $\mathrm{K}_{2} \mathrm{O}$ & $10-11$ \\
\hline Aluminium as $\mathrm{Al}_{2} \mathrm{O}_{3}$ & $9-11$ \\
\hline Iron as $\mathrm{Fe}_{2} \mathrm{O}_{3}$ & $3-11$ \\
\hline Loss on ignition at $1000^{\circ} \mathrm{C}$ & $1-3$ \\
\hline
\end{tabular}




\subsection{SAMPLES PREPARATION}

Due to the importance of having samples made at the same level of industrial production standards, the composites were prepared by using the industrial lab of Gossen Company.

\subsubsection{Mixing}

PVC foam compounds were prepared using a high shear mixer (Gunther Pepenmeier, Machinen-u. Detmoid, Type: TSHK). Initially, the PVC resin was added to the mixer at room temperature. Then, the stabilizer was added at $52^{\circ} \mathrm{C}$; processing aids were added at $58^{\circ} \mathrm{C}$. Finally, the lubricants and the blowing agents were added at $66^{\circ} \mathrm{C}$. When the temperature reached $100^{\circ} \mathrm{C}$, the compound was collected from the mixer and allowed to cool down to room temperature before extrusion.

\subsubsection{Extrusion}

The compounds were extruded using a 1.25 inch, 20:1 (L/D) single screw extruder (Themoplast Extrusion Machine) at a screw speed of $60 \mathrm{rpm}$. The heating zones temperatures were in the range of $158^{\circ} \mathrm{C}$ to $175^{\circ} \mathrm{C}$.A rectangular profile die was used to extrude the samples. The extruded stream was air cooled prior to feeding through an aluminum sizer (1" x $0.28 ")$ placed in a vacuum chilled water 
tank. Finally, the extruded stream was cut into 12" pieces using an automated cutter.

\subsection{CHARACTERIZATION METHODS}

In order to study the effect of adding reinforcing solids to the PVC foam, several types of tests were run on the samplesby using the facilities of UWMilwaukee at the College of Engineering and Applied Sciences.These tests are as follows:

\subsubsection{Thermal characterization}

Thermal and thermal mechanical properties of the foam composites were analyzed using:

\subsubsection{Thermo-Gravimetric Analysis (TGA)}

TA Instrument SDT 2960 thermo-gravimetric analysis equipment (TGA), located in the AAF, was used to measure the weight loss versus temperature, the Primary Degradation Temperature (PDT), and Secondary Degradation Temperature (SDT) of the foam composites. The foam composite samples weighing 10 to $30 \mathrm{mg}$ were heated in standard pans in a temperature range of 25 to $800{ }^{\circ} \mathrm{C}$ at a heating rate of $10^{\circ} \mathrm{C} / \mathrm{min}$ under argon atmosphere. 


\subsubsection{Differential Scanning Calorimetry (DSC)}

DSC measurements were collected by using TA Q2000 analyzer, located in the Polymers Lab. Foam composite samples weighing 5 to $10 \mathrm{mg}$ were heated in standard aluminum pans in the temperature range of 25 to $260{ }^{\circ} \mathrm{C}$ at a heating rate of $10^{\circ} \mathrm{C} / \mathrm{min}$.

\subsubsection{Dynamic Mechanical Analysis (DMA)}

The test was performed on TA Instrument Q800, located in the AAF,to evaluate the viscoelastic properties (storage modulus, loss modulus, and $\tan \delta$ ) of composites in the solid state. A three-point bending mode was used at a test temperature range of 25 to $120^{\circ} \mathrm{C}$ at a constant heating rate of $3^{\circ} \mathrm{C} / \mathrm{min}$ and a dynamic force at a frequency of $1 \mathrm{~Hz}$. The samples were prepared according to ASTM International Standard D4440.

\subsubsection{Dimensional Stability}

The dimensional stability of the foam composites was analyzed according to the American Architectural Manufacturers Association (AAMA) standards. Extruded samples were heated by using Fisher Scientific Oven (700 Series), located in the $201 \mathrm{Lab}$. The original dimensions of the foam composites were 12 " $\mathrm{x}$ $1 " \mathrm{x} 0.28$ ". The change in length was measured after 4 hours and the percent 
shrinkage was determined according to equation (1), where $l_{o}$ and $l_{f}$ are the initial and final lengths, respectively:

$$
\% \text { Shrinkage }=\frac{l_{0}-l_{f}}{l_{0}} \times 100 \quad \mathbf{1}
$$

Heat resistance of the composites was also analyzed according to AAMA standards. Extruded samples were heated in the same oven that mentioned above at $141^{\circ} \mathrm{C}$ for 30 minutes. The original dimensions of the foam composites were $12 \mathrm{x}$ $1 " x$ 0.28". The samples were cooled for 4 hours and a visual inspection was done to determine the presence of any flaws or distortion in the samples.

\subsubsection{Mechanical Properties}

\subsubsection{Tensile Testing}

Tensile properties like Ultimate Tensile Strength (UTS) and extension at the break were determined using Instron 3365 universal testing machine, located in the Structural Lab,on rectangular specimens measuring 12 "x1"x0.28" at a crosshead speed of $0.5 \mathrm{in} / \mathrm{min}$.

\subsubsection{Compressive Testing}

Compressive properties were determined using the Instron 3365 universal testing machine, located in the Structural Lab, on rectangular cross section area specimens (1"x0.28") at a crosshead speed of $0.08 \mathrm{in} / \mathrm{min}$. 


\subsubsection{Flexural testing}

Flexural properties were determined using Instron 3365, with a three-point bending test set-up on rectangular specimens measuring 8"x1"x0.28" at a crosshead speed of $0.5 \mathrm{in} / \mathrm{min}$. The span length was kept at 4 inches. The flexural stress and strains were calculated using equations (2) and (3):

$$
\begin{array}{ll}
\sigma_{f}=\frac{3 P L}{2 b d^{2}} & 2 \\
\varepsilon_{f}=\frac{6 D d}{L^{2}} & 2
\end{array}
$$

Where, $\sigma_{f}$ and $\varepsilon_{f}$ are the respective flexural stress and strain at the midpoint, and $P, L, b, d, D$ are the load, span length, specimen width, specimen thickness and midpoint deflection, respectively. The flexural strength was determined using the maximum stress value recorded before sample fracture and flexural modulus was determined by the slope of the initial linear region of the stress-strain curve.

\subsubsection{Impact Testing}

Charpy impact properties were determined using Tinus Olsen impact testing machine (model IT 504), located in the Center for Composite Materials,with respect to ASTM D 6110. Four samples of each composite were tested. The 
dimensions of the impact testing samples were $5 " \mathrm{x} 0.5^{\prime \prime} \times 0.28^{\prime \prime}$ with a $45^{\circ}$ notch at the middle.

\subsubsection{Scanning Electron Microscopy}

Topcon SM-300 SEM was used for imaging and microstructural analysis of the extruded PVC foam composites. The specimens were fractured in liquid nitrogen and coated using a sputter coater to minimize the charging effect and to improve the conductivity of the samples prior to analysis. 


\section{CHAPTER 3}

\section{E-GLASS FIBER}

\subsection{PVC-GF FOAM COMPOSITES FORMULATION}

During the fabrication of PVC-GF foam composite materials, besides the matrix and the reinforcing phase, additional components were added to make the foam composites like stabilizers, foam blowing agents, and other additives, see Table 4.

Table 4: PVC- GF foam composites formulation

\begin{tabular}{|c|c|c|c|c|c|c|}
\hline \multicolumn{2}{|c|}{ Glass Fiber } & $\begin{array}{l}\text { PVC } \\
\text { Resin }\end{array}$ & Stabilizer & $\begin{array}{l}\text { Blowing } \\
\text { Agents }\end{array}$ & Lubricants & $\begin{array}{l}\text { Processing } \\
\text { Aid }\end{array}$ \\
\hline \multicolumn{7}{|c|}{ Content (wt. \%) } \\
\hline \multicolumn{2}{|c|}{0} & 92.5 & \multirow{9}{*}{0.85} & \multirow{9}{*}{0.5} & \multirow{9}{*}{0.6} & \multirow{9}{*}{6} \\
\hline \multirow{4}{*}{$1 / 16^{\prime \prime}$} & 5 & 87.5 & & & & \\
\hline & 10 & 82.5 & & & & \\
\hline & 15 & 77.5 & & & & \\
\hline & 20 & 72.5 & & & & \\
\hline \multirow{4}{*}{$1 / 32^{\prime \prime}$} & 5 & 87.5 & & & & \\
\hline & 10 & 82.5 & & & & \\
\hline & 15 & 77.5 & & & & \\
\hline & 20 & 72.5 & & & & \\
\hline
\end{tabular}




\subsection{RESULTS AND DISCUSSION}

\subsubsection{Thermal Properties}

Dimensional stability of the foam composites was measured as a percentage of shrinkage; the effect of GF lengths and loading is presented in Figure3.The percentage of shrinkage decreasedby $22.5 \%$ and $28.4 \%$ when adding $5 \%$ of $1 / 32^{\prime}$ and $1 / 16^{\prime}$ GFs, respectively, compared with pristine samples. It is evident that dimensional stability increases significantly with increasing the glass fiber content in the composites. This is due to the higher solid content in the polymer matrix, which has higher resistance to dimensional changes under thermal effect. A comparison between the samples made with the same filler content at different GF lengths reveals that the composites containing longer glass fibers (1/16") exhibit higher dimensional stability improvement than thosewith shorter glass fibers. This may be attributed to a higher interlocking and bonding between longer glass fibers and the foam matrix along the fiber length. Since glass fibers have lowercoefficient of thermal expansion than the polymer matrix, higher interlocking between the fibers and the matrix improves dimensional stability of the composites[25].Overall, the dimensional stability of the foam composites at $20 \%$ concentration of GFs (1/32" and $1 / 16 ")$ improved by $60 \%$ and $65 \%$, respectively.

Although the attained improvements in dimensional stability of the composites were evaluated by a short-term shrinkage test, it is expected that the dimensional stability of long-term shrinkage will improve, as well. This could be 
explained based on the effect of the bonding between the reinforcing phase and the matrix;thisrestricts the mobility of polymer chains [35], which consequently enhances the durability of the composites. The restriction of the polymer chains increases with increasing the interfacial surface between the fibers and the matrix.

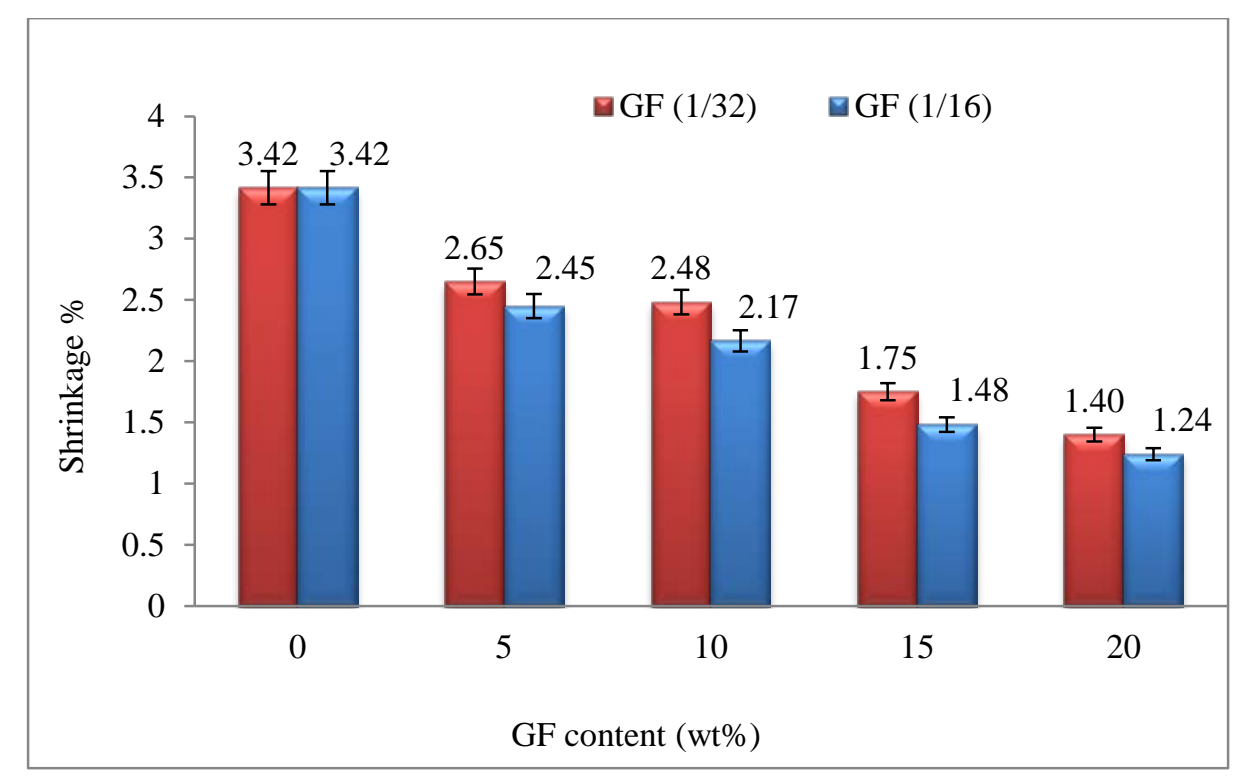

Figure 3: Dimensional stability of PVC-GF foam composites

Heat resistance was evaluated qualitatively by visual inspectionfor surface flaws and shape distortion of the extruded samples after subjection to a heating and cooling cycle. Although, the testsamples did not show any flakes or cracks on the surface, some distortion was observed on the sides, as shown in Figure 4. 

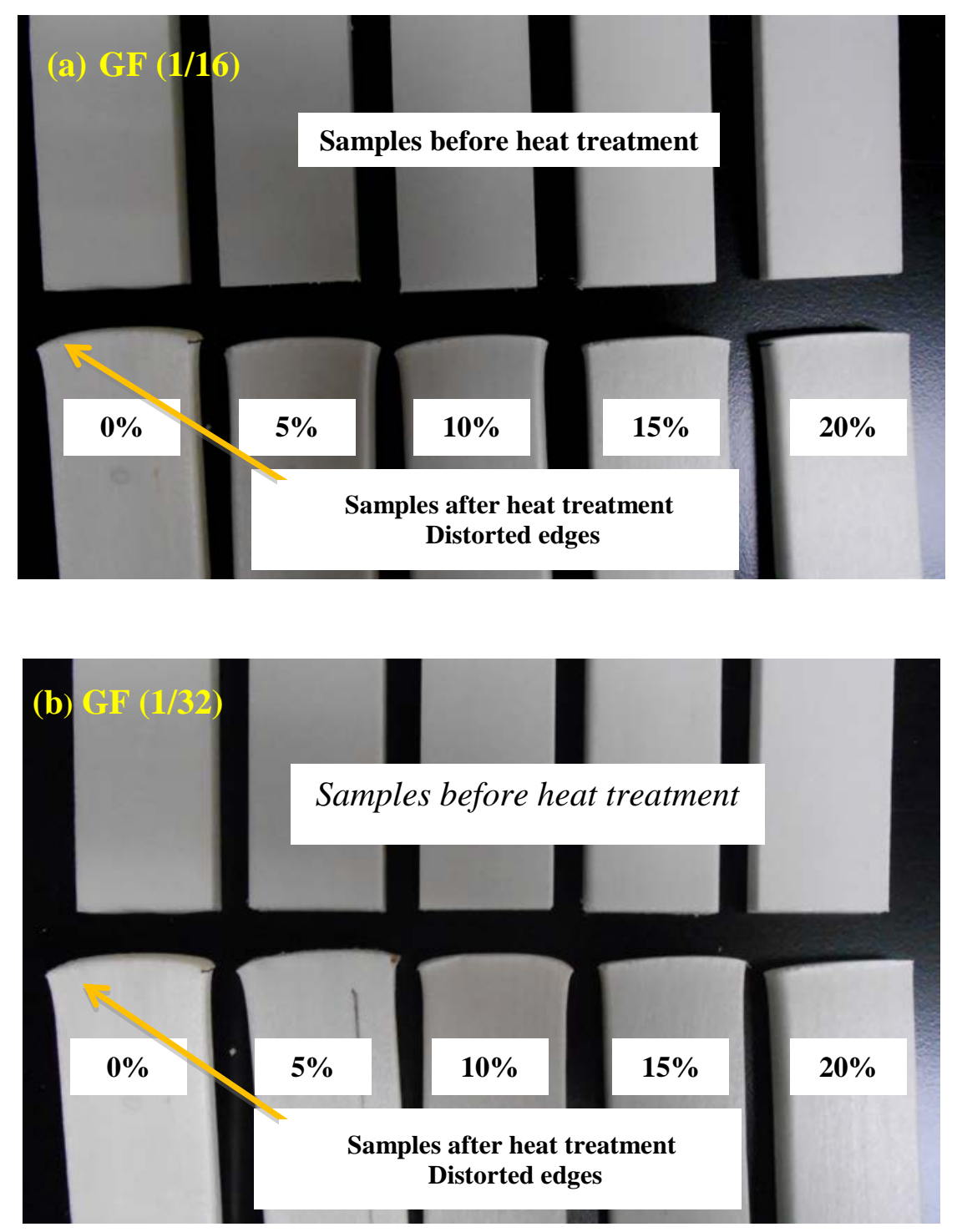

Figure 4: Distortion in PVC-GF foam composites before and after heat treatment.(a) $1 / 16^{\prime \prime}$ (b) $1 / 32^{\prime \prime}$

It was also observed that the addition of glass fibers reducedthe amount of distortion. In addition, the composites containing 1/16" GFs exhibited higher heat resistance when compared with those containing shorter GF lengths. Meanwhile, the addition of glass fibers does not seem to affect the glass transition temperature 
(Tg) of the PVC foam composites, around $82{ }^{\circ} \mathrm{C}$, as shown in Table 5. Similar conclusions were presented by Hassan et al. [17]

Table 5: Glass transition temperatures of the PVC-GF foam composites measured by DSC

\begin{tabular}{|c|c|c|c|c|c|c|c|c|c|}
\hline GF wt\% & $0 \%$ & \multicolumn{2}{|c|}{$5 \%$} & \multicolumn{2}{c|}{$10 \%$} & \multicolumn{2}{c|}{$15 \%$} & \multicolumn{2}{c|}{$20 \%$} \\
\hline Fiber Length & N/A & $1 / 16^{\prime \prime}$ & $1 / 32 "$ & $1 / 16^{\prime \prime}$ & $1 / 32^{\prime \prime}$ & $1 / 16^{\prime \prime}$ & $1 / 32^{\prime \prime}$ & $1 / 16 "$ & $1 / 32 "$ \\
\hline $\operatorname{Tg}\left({ }^{\circ} \mathrm{C}\right)$ & 82.21 & 82.47 & 81.93 & 82.97 & 83.8 & 81.89 & 83.12 & 81.56 & 82.3 \\
\hline
\end{tabular}

The results from TGA analysis of PVC-GF foam composites are presented in Figure 5. The average Primary Degradation Temperature (PDT) of the foam composites begins around $277{ }^{\circ} \mathrm{C}$, while the average Secondary Degradation Temperature (SDT) is around $440{ }^{\circ} \mathrm{C}$.

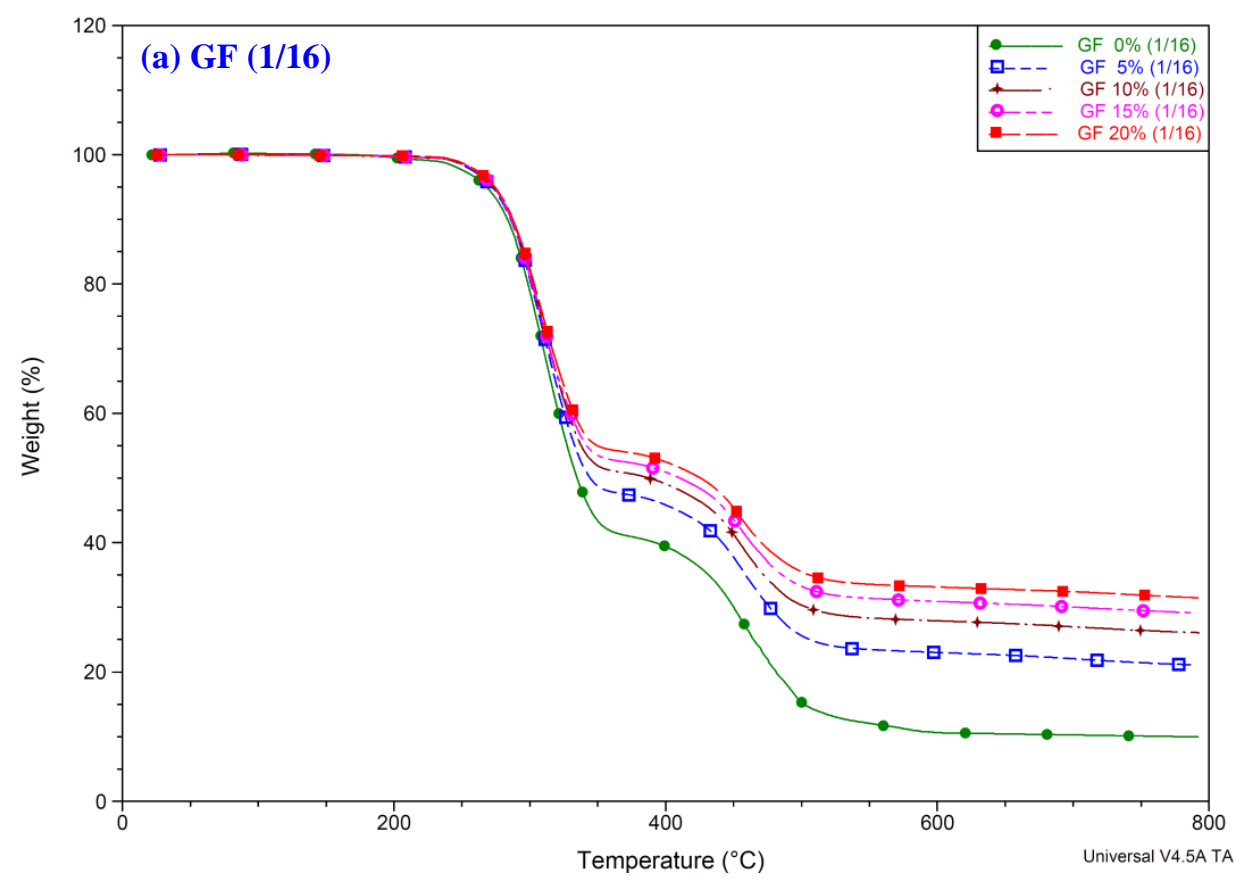




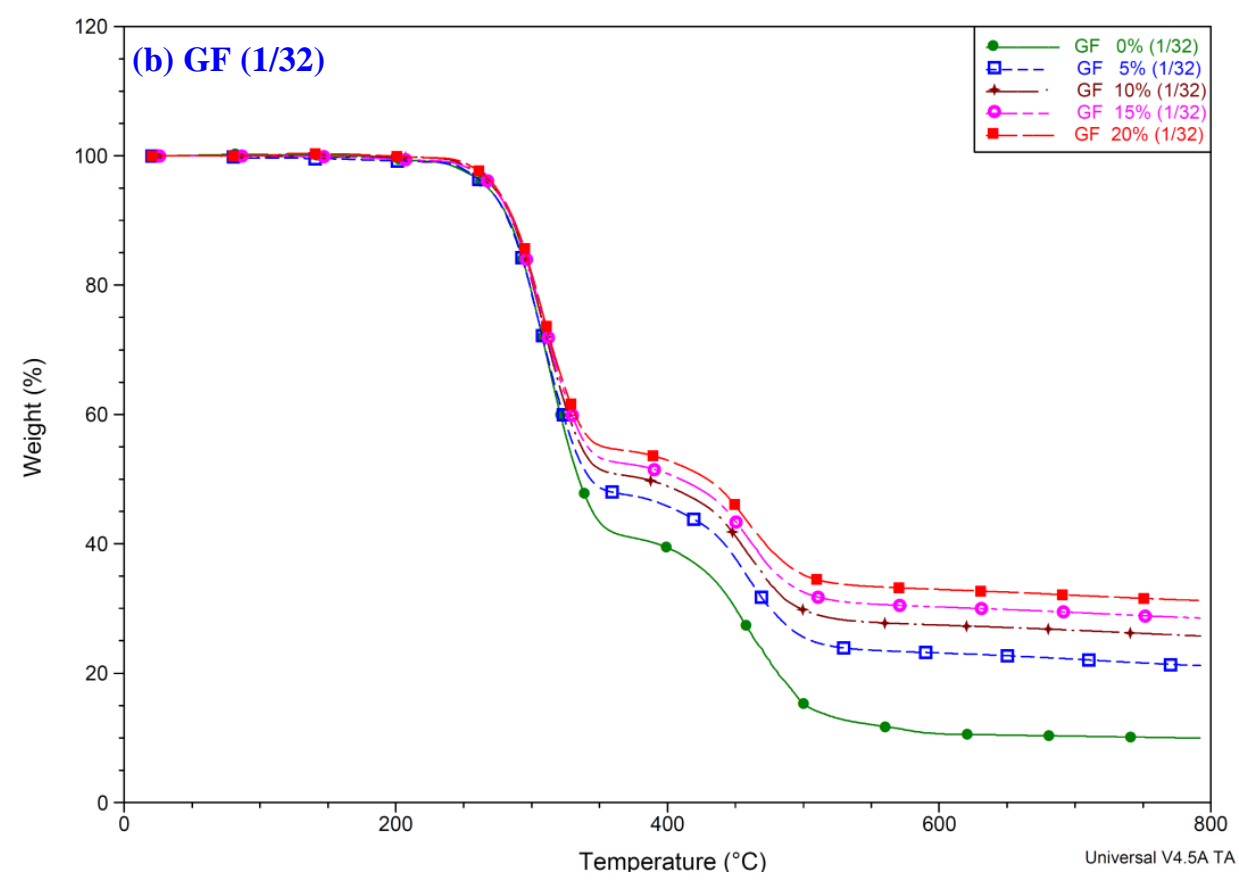

Figure 5: TGA analysis of PVC-GF foam composites (a) 1/16" (b) 1/32"

Increasing glass fibers'content increases the secondary decomposition temperature of the composites, as shown in Table 6, which means that it takes more energy to break the hydrocarbon backbone of the polymer matrix [30]. On the other hand, the primary degradation temperature of the composites, which indicates the start of the separation process of chlorine from the polymer chains, decreases slightly by increasing the GF content. This can be attributed to the higher thermal conductivity of GF, which results in faster heat transfer into the PVC matrix and thermal degradation starting at lower temperatures. The residual weight at $800{ }^{\circ} \mathrm{C}$ is found to increase with increasing GF content due to the higher content of inorganic filler in the matrix. 
Table 6: Primary and Secondary Decomposition Temperature of PVC-GF foam composites

\begin{tabular}{|c|c|c|c|}
\hline \multicolumn{2}{|c|}{ Glass Fiber } & $\begin{array}{c}\text { Primary Decomposition } \\
\text { Temperature }\left({ }^{\circ} \mathrm{C}\right)\end{array}$ & $\begin{array}{c}\text { Secondary Decomposition } \\
\text { Temperature }\left({ }^{\circ} \mathrm{C}\right)\end{array}$ \\
\hline \multicolumn{2}{|c|}{$0 \%$} & 279.39 & 442.25 \\
\hline \multirow{4}{*}{$1 / 16 "$} & $5 \%$ & 278.21 & 439.36 \\
\cline { 2 - 4 } & $10 \%$ & 278.57 & 441.78 \\
\cline { 2 - 4 } & $15 \%$ & 276.73 & 440.63 \\
\cline { 2 - 4 } & $20 \%$ & 277.31 & 439.04 \\
\hline \multirow{4}{*}{$1 / 32 "$} & $5 \%$ & 276.66 & 436.23 \\
\cline { 2 - 4 } & $10 \%$ & 277.15 & 437.73 \\
\cline { 2 - 4 } & $15 \%$ & 277.23 & 437.85 \\
\cline { 2 - 4 } & $20 \%$ & 277.27 & 443.67 \\
\hline
\end{tabular}

Thermo mechanical properties of the PVC-GF composites were determined by DMA analysis. Variations in the storage modulus (E'), which represents the elastic behavior, and the loss modulus (E"), which represents the viscous behavior, with temperature, are shown in Figures 6 and 7, respectively. The storage modulus $\left(E^{\prime}\right)$ and the peak intensity of the loss modulus (E") increased with the addition of GFs for both GF lengths (1/32" and 1/16"). This is attributed to the enhancement in the energy dissipation ability in the presence of solid fillers in the polymer matrix and the increase in the polymer-filler and filler-filler slippages at $\mathrm{Tg}$ [32]. However, at $20 \mathrm{wt} \%$ GF concentration, the magnitude of $\mathrm{E}^{\prime}$ and $\mathrm{E}$ " decrease due to the agglomeration of GFs at higher concentrations, as shown by SEM analysis (Figure $9 \mathrm{~d})$. The agglomeration of GFs leads to higher friction between the fibers and less interaction between the reinforcing phase and the host matrix. Consequently, the energy dissipation in the reinforced polymer matrix is reduced [31]. 
Similarly, the composites with 1/16" GFs exhibit higher storage and loss moduli compared to the 1/32" GFs. The storage modulus increased from 225 MPa to $675 \mathrm{MPa}$ with the addition of $10 \% 1 / 16 "$ GFs; whereas itincreased only to 575 MPa with the addition of 15\% 1/32" GFs. The loss modulus (E") peak increased to from 60 MPa to $95 \mathrm{MPa}$ and $83 \mathrm{MPa}$ in the case of 15\%-1/16" and 15\%-1/32" GFs, respectively. This is also attributed to the higher energy dissipation in the presence of longer glass fibers due to higher interlocking between the fibers and the polymer matrix. 

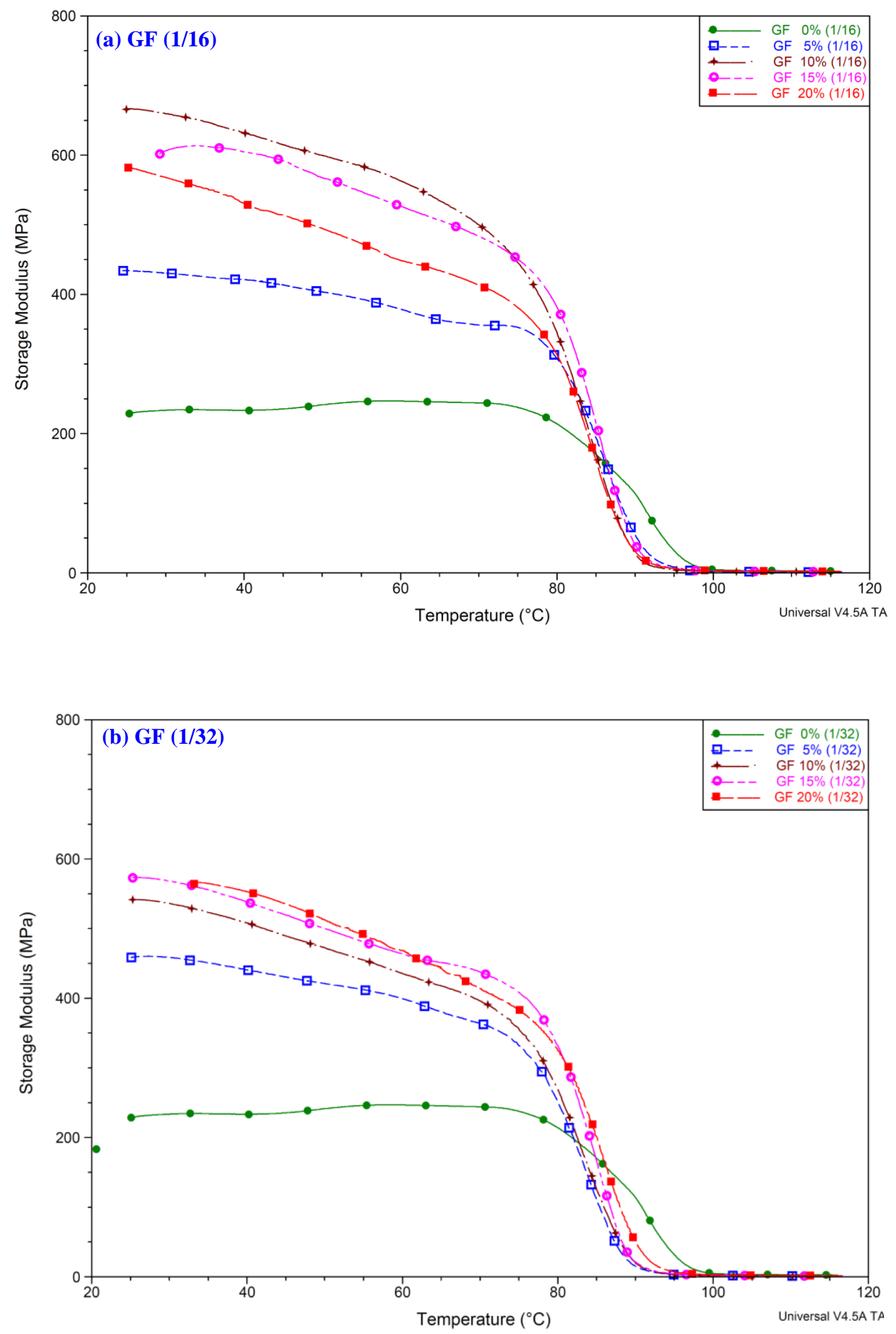

Figure 6: Storage Modulus (E') of PVC-GF foam composites (a) 1/16", (b) 1/32". 
29
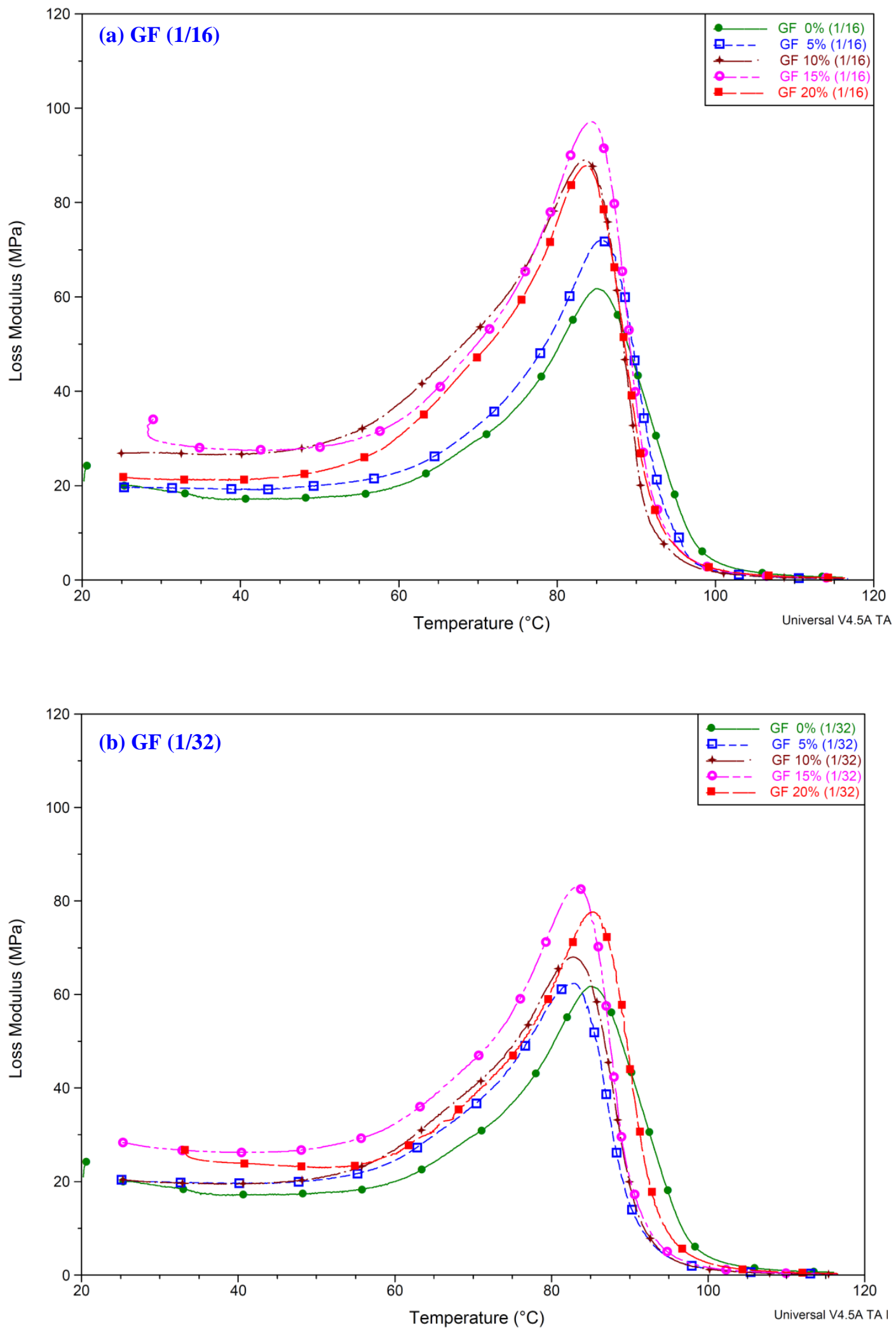

Figure 7:Loss Modulus (E") of PVC-GF foam composites (a) 1/16" (b) 1/32". 


\subsubsection{Mechanical Properties}

The mechanical properties of polymer GF composites highly depend on the geometry of the reinforcement phase; such as the length and diameter of the glass fibers [19]. Table 7 summarizes the effect of glass fiber length and content on the mechanical properties of PVC-GF composites. Since the bonding between GFs and the polymer foam occurs only through the cell walls, the enhancement in the foam strength is limited and is greatly affected by the bonding strength between the two surfaces. However, longer fibers are likely to have more bonding sites due to higher penetration through the walls of the closed cell foams. The ultimate tensile strength (UTS) of the composite foams seems to maintain its value at different loadings of GF. Meanwhile, the composites made with longer glass fibers (1/16") seem to have slightly higher UTS at all loading levels.

In order to study the behavior of the composites under various loading situations, compressive testing wasperformed on the samples as well. From Table 7, it can be noticed that the change in compressive strength of the composites was insignificant. This can be attributed to the fact that most of the fibers tend to align toward the extrusion direction despite the random orientation, along with direction of the uniaxial compressive load. This limits the load's distribution and raises the brittle effect of the reinforcing phase. This can be seen clearly with increasing the content of the reinforcing phase to $20 \%$ in addition to the effect of the agglomeration of GFs. However, longer glass fibers (1/16") seem to have higher performance, due to higher penetration through the walls of the closed cell foams.A similar effect of the glass fibers length on the UTS and the compressive strength is also visible with the flexural strength measurements, as shown in Table7. However, the failure of the tested 
composites occurred on thesample'supper surface, which is under compression stress and could indicate a localized loading failure.

Table 7: Mechanical properties of PVC-GF foam composites*

\begin{tabular}{|c|c|c|c|c|c|c|}
\hline \multicolumn{2}{|c|}{ Glass Fiber } & $\begin{array}{c}\text { UTS } \\
\text { (MPa) }\end{array}$ & $\begin{array}{c}\text { Extension } \\
\text { at Break } \\
\mathbf{( m m )}\end{array}$ & $\begin{array}{c}\text { Compressive } \\
\text { Strength } \\
\mathbf{( M P a})\end{array}$ & $\begin{array}{c}\text { Flexural } \\
\text { Strength } \\
\mathbf{( M P a})\end{array}$ & $\begin{array}{c}\text { Impact } \\
\text { Strength } \\
\left(\mathbf{J} / \mathbf{m}^{2}\right)\end{array}$ \\
\hline \multicolumn{2}{|c|}{$0 \%$} & 8.17 & 43.43 & 12.07 & 17.26 & 30.13 \\
\hline \multirow{3}{*}{$1 / 16 "$} & $5 \%$ & 8.91 & 38.08 & 11.21 & 17.92 & 33.08 \\
\cline { 2 - 7 } & $10 \%$ & 8.56 & 28.25 & 11.28 & 16.68 & 29.81 \\
\cline { 2 - 7 } & $15 \%$ & 8.69 & 27.45 & 11.24 & 16.13 & 28.89 \\
\cline { 2 - 7 } & $20 \%$ & 8.55 & 25.41 & 10.67 & 18.58 & 25.47 \\
\hline \multirow{3}{*}{$1 / 32 "$} & $5 \%$ & 8.68 & 37.80 & 7.6 & 16.59 & 30.92 \\
\cline { 2 - 7 } & $10 \%$ & 8.28 & 33.20 & 9.88 & 15.70 & 29.06 \\
\cline { 2 - 7 } & $15 \%$ & 8.44 & 33.16 & 9.44 & 17.00 & 23.75 \\
\cline { 2 - 7 } & $20 \%$ & 8.31 & 30.83 & 8.79 & 16.19 & 21.58 \\
\hline
\end{tabular}

The ductility of the PVC-GF composites, measured by the extension at break, was noticed to decrease in the presence of glass fibers. Higher amounts of GFs in the polymer matrix render the composite more brittle and prone to brittle fracture as they are dispersed in the matrix with no specific orientation. Longer glass fibers (1/16") exhibit higher reduction in ductility compared to the shorter fibers; this is also attributed to the higher penetration of the longer fibers in the walls of the closed cell foams which increases the stiffness of the structure.

* The values of standard deviation are as below
\begin{tabular}{|c|c|c|c|c|}
\hline UTS & $\begin{array}{c}\text { Extension } \\
\text { at Break }\end{array}$ & $\begin{array}{c}\text { Compressive } \\
\text { Strength }\end{array}$ & $\begin{array}{c}\text { Flexural } \\
\text { Strength }\end{array}$ & $\begin{array}{c}\text { Impact } \\
\text { Strength }\end{array}$ \\
\hline 0.23 & 5.85 & 1.43 & 0.91 & 3.70 \\
\hline
\end{tabular}


The impact strength of the PVC-GF composites decreases with the addition of GFs in both lengths. In the case of 1/16" GFs, the impact strength decreased from 33 $\mathrm{J} / \mathrm{m}^{2}$ at $5 \% \mathrm{GF}$ to $25 \mathrm{~J} / \mathrm{m}^{2}$ at $20 \% \mathrm{GF}$ - a $24 \%$ reduction. However, the reduction in impact strength in the case of 1/32" GFs was higher at 29\%, i.e., $31 \mathrm{~J} / \mathrm{m}^{2}$ at $5 \%$ GF and $22 \mathrm{~J} / \mathrm{m}^{2}$ at $20 \% \mathrm{GF}$. The longer fibers tend to strengthen the composite matrix due to their penetration across multiple cell walls and interlocking between the fibers themselves, which leads to better load distribution [28].

\subsubsection{Microstructural Morphology}

The dispersion and surface bonding of the solid phase with the host polymer matrix affects many important characteristics; such as mechanical properties and dimensional stability [21, 31]. Therefore, it is important to study the fiber-matrix interface in order to explain the characteristics and behavior of these composites. Figure 8 (a)-(d) shows the dispersion of 1/16" GFs in the PVC foam matrix at 50x magnification; whereas Figure 9 (a)-(d) shows the dispersion of 1/32" GFs in the PVC foam matrix at 150x magnification. One can observe in both sets of micrographs the random orientation and dispersion of glass fibers in the matrix, and the penetration of the long fibers through the closed cell walls. In the case of $1 / 16 "$ GFs, the penetration is across multiple cell walls, as shown in Figure 8 (c); whereas the penetration in the case of 1/32" GFs is mostly limited to individual cell walls, as shown in Figure 9(c). Fiber dispersion is a function of the fiber lengths; shorter fibers tend to agglomerate more than the longer fibers during processing due to the liquid additives used in the compounding process. 

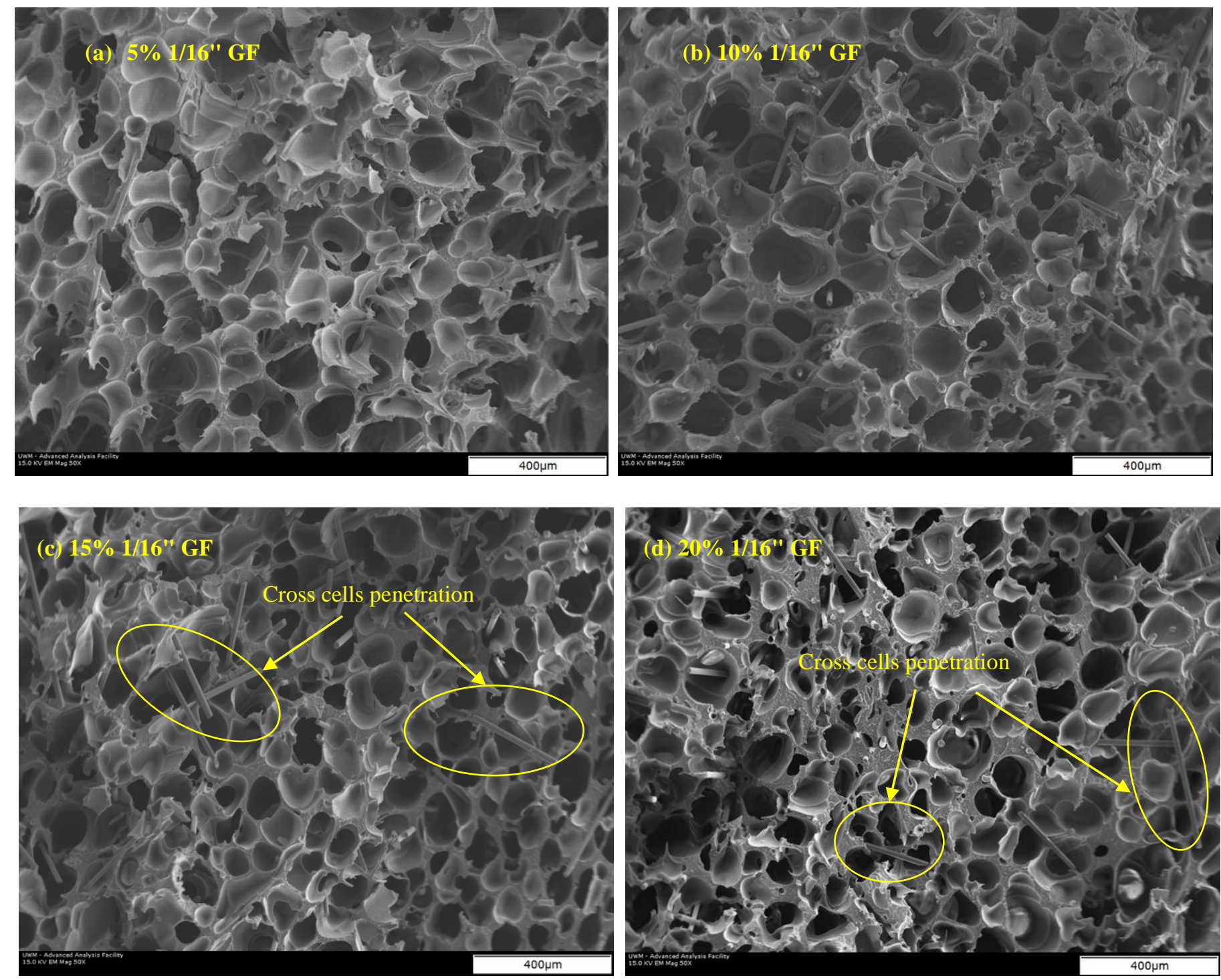

Figure 8:SEM micrographs at 50x of 1/16" PVC-GF foam composites: (a) 5\% (b) 10\% (c) 15\% (d) 20\%. 

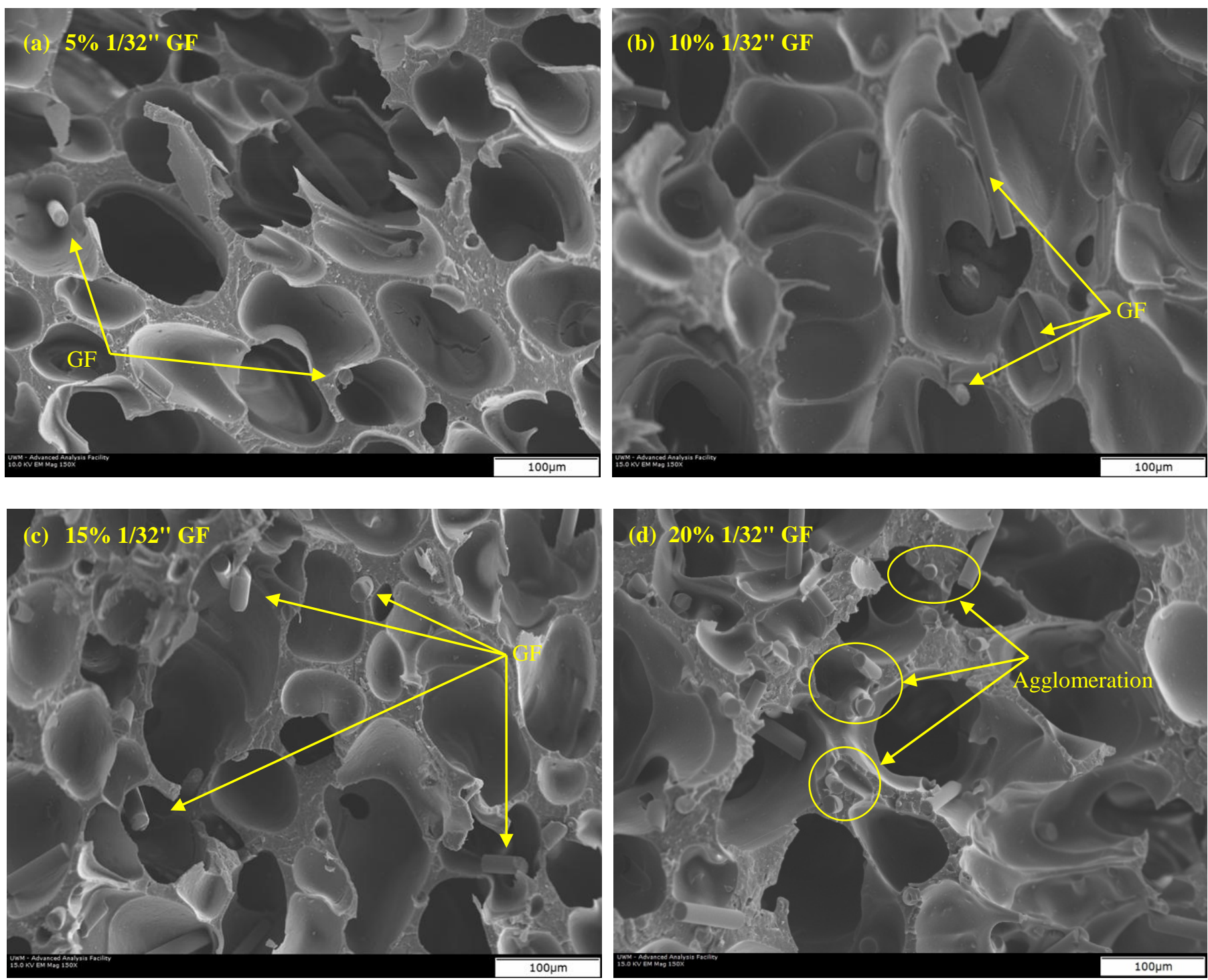

Figure 9: SEM micrographs at 150x of 1/32" PVC-GF foam: (a) 5\% (b) 10\% (c) 15\% (d) $20 \%$ 
Figure 10 shows a close up image of a fiber-matrix interface at $1000 \mathrm{x}$ magnification. The orientation of this particular fiber is along the fracture surface, whereas the majority of fibers which are present in the foam matrix are across the fracture surfaces. However, the fracture surface shown in Figure 10 seems to be clean, which indicates poor bonding between the two surfaces. In addition, the diameter of the glass fiber seems to be close to the thickness of the cell wall or higher at some locations. Both these observations may be significant to the effect of glass fibers on the mechanical and thermal performance of the composite matrix.

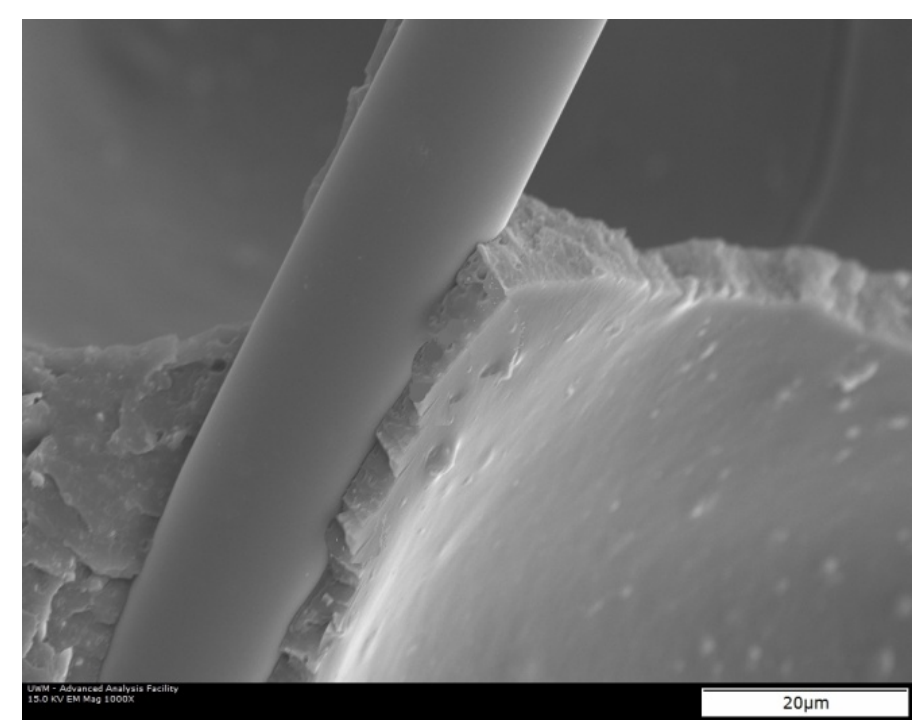

Figure 10: SEM micrograph at 1000x of a glass fiber interface with PVC foam 


\section{CHAPTER 4}

\section{PHLOGOPITE MICA}

\subsection{PVC-MICA FOAM COMPOSITES FORMULATION}

During the fabrication of PVC-Mica foam composite materials, besides the matrix and the reinforcing phase, additional components were added to make the foam composites like stabilizers, foam blowing agents, and other additives, see Table 8.

Table 8: PVC-Mica foam composites formulation

\begin{tabular}{|c|c|c|c|c|c|}
\hline Mica & PVC Resin & Stabilizer & $\begin{array}{c}\text { Blowing } \\
\text { Agents }\end{array}$ & Lubricants & $\begin{array}{c}\text { Processing } \\
\text { Aid }\end{array}$ \\
\hline \multicolumn{6}{|c|}{ Content (wt. \%) } \\
\hline 0 & 92.5 & \multirow{5}{*}{0.85} & \multirow{5}{*}{0.5} & \multirow{5}{*}{0.6} & \multirow{5}{*}{6} \\
\hline 5 & 87.5 & & & & \\
\hline 10 & 82.5 & & & & \\
\hline 15 & 77.5 & & & & \\
\hline 20 & 72.5 & & & & \\
\hline
\end{tabular}

\subsection{RESULTS AND DISCUSSION}

\subsubsection{Thermal Properties}

Dimensional stability of the foam composites was assessed as a percentage of linear shrinkage of the extruded foam composites when heated to $82{ }^{\circ} \mathrm{C}$ for 30 
minutes, as shown in Figure 11. It is evident that increasing the percentage of mica reduces the thermal shrinkage of the PVC-Mica composites from an initial value of $3.4 \%$ to $1.9 \%$ in samples reinforced with $20 \%$ mica, which accounts for a net reduction of $44 \%$. Since mica has lower thermal expansion coefficient than PVC, higher interfacial bonding between mica platelets and the foam matrix improves dimensional stability of the composites. The reduction in shrinkage with the addition of mica is nonlinear. Samples containing 5\% mica barely show improvement in dimensional stability when compared to the pristine PVC foam. However, increasing the amount of mica in the composite samples decreases the shrinkage in the samples. The highest drop in shrinkage can be observed as the amount of mica is increased above $15 \%$ in the samples. It is hence expected that adding mica above $20 \%$ in the composites can further reduce the shrinkage due to the high dimensional and thermal stability of mica itself [6, 34].

Although the attained improvements in dimensional stability of the composites were evaluated by a short-term shrinkage test, it is expected that the dimensional stability of long-term shrinkage will improve as well. This could be explained based on the effect of the bonding between the reinforcing phase and the matrix; this restricts the mobility of polymer chains [35], which consequently enhances the durability of the composites. The restriction of the polymer chains increases with increasing the interfacial surface between the fibers and the matrix. In addition, adding mica can hinder the thermal degradation by decreasing the total diffusivity of oxygen and volatiles formed in the matrix. Moreover, the amount of 
UV is reduced in the composites due to the opaqueness property of Phlogopite mica.

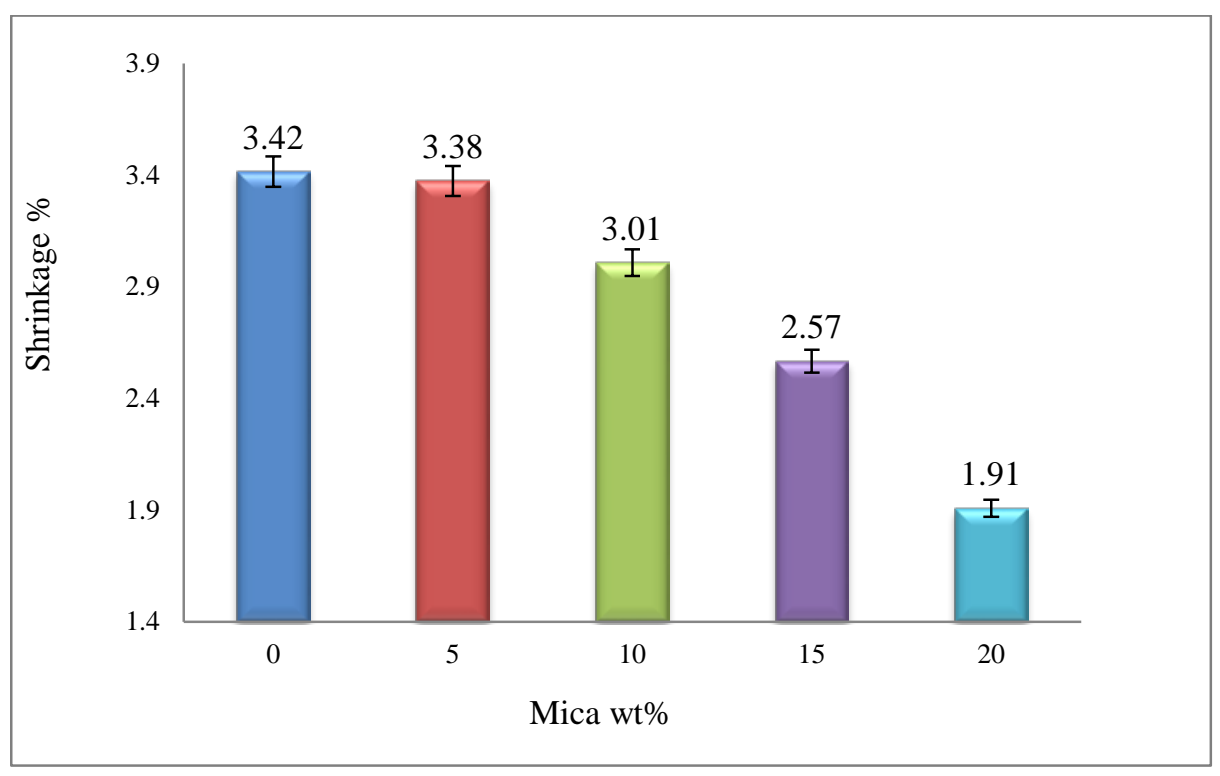

Figure 11: Dimensional stability of PVC-Mica foam composites

Heat resistance was evaluated qualitatively by visual inspection for surface flaws and shape distortion of the extruded samples after a heating and cooling cycle. Although, the test samples did not show any flakes or cracks on the surface, some distortion was observed on the edges as shown in Figure 12.

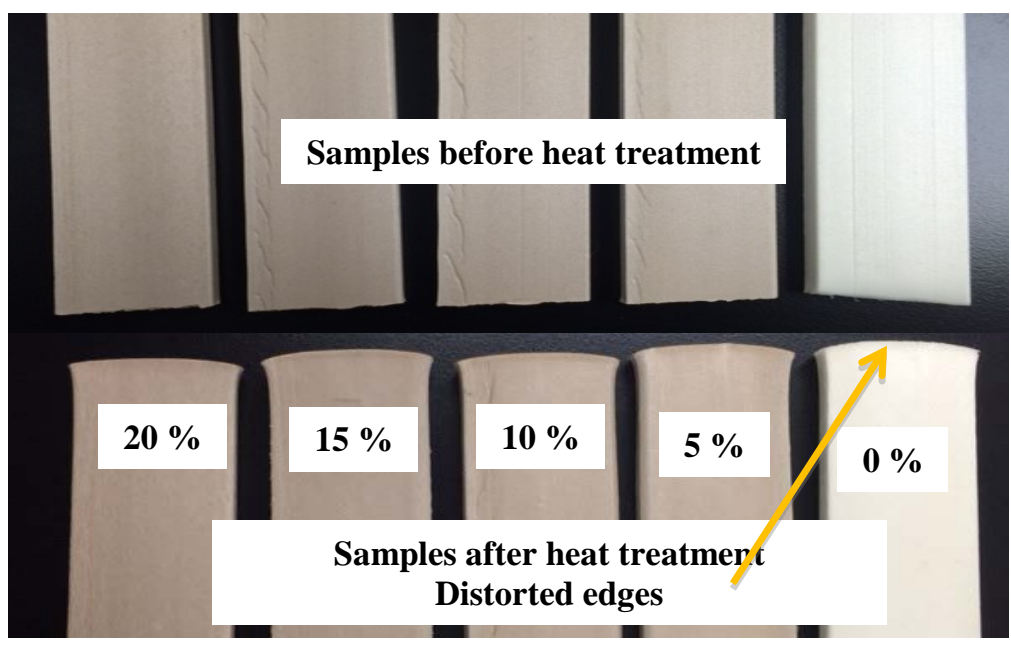

Figure 12: Distortion in PVC-Mica foam composites before and after heat treatment. 
Although increasing the amount of mica in the composites decreased the shape distortion due to the high thermal resistance of mica, the addition of mica did not seem to affect the glass transition temperature $\left(\mathrm{T}_{\mathrm{g}}\right)$ of the composites. The $\mathrm{T}_{\mathrm{g}}$ remained around $83^{\circ} \mathrm{C}$ as is shown in Table 8 .

Table 9: Glass transition temperatures of PVC-Mica foam composites determined by DSC

\begin{tabular}{|c|c|c|c|c|c|}
\hline Sample & $\mathbf{0 \%}$ & $\mathbf{5 \%}$ & $\mathbf{1 0 \%}$ & $\mathbf{1 5 \%}$ & $\mathbf{2 0 \%}$ \\
\hline $\boldsymbol{T}_{\boldsymbol{g}}\left({ }^{\mathbf{o}} \mathbf{C}\right)$ & 82.2 & 83.9 & 83.3 & 83.4 & 82.9 \\
\hline
\end{tabular}

The results from TGA analysis of PVC-Mica foam composites are presented in Figure 13. The average Primary Degradation Temperature (PDT) of the foam composites begins around $273{ }^{\circ} \mathrm{C}$, while the average Secondary Degradation Temperature (SDT) is around $443{ }^{\circ} \mathrm{C}$. As shown in Table 10, increasing the amount of mica increases the SDT of the composites, which means that it takes more energy to break the hydrocarbon backbone of the polymer matrix $[27,28]$. On the other hand, PDT of the composites, which indicates the decomposition of chlorine from the polymer chains, decreases slightly by increasing the mica content. This can be attributed to the higher thermal conductivity of mica, which results in faster heat transfer into the PVC matrix lowering the thermal degradation temperatures. The residual weight at $800{ }^{\circ} \mathrm{C}$ was found to increase as the amount of mica increased in the composites, which clearly indicates the presence of higher amounts of the inorganic filler in the matrix, as shown in Table 10. 


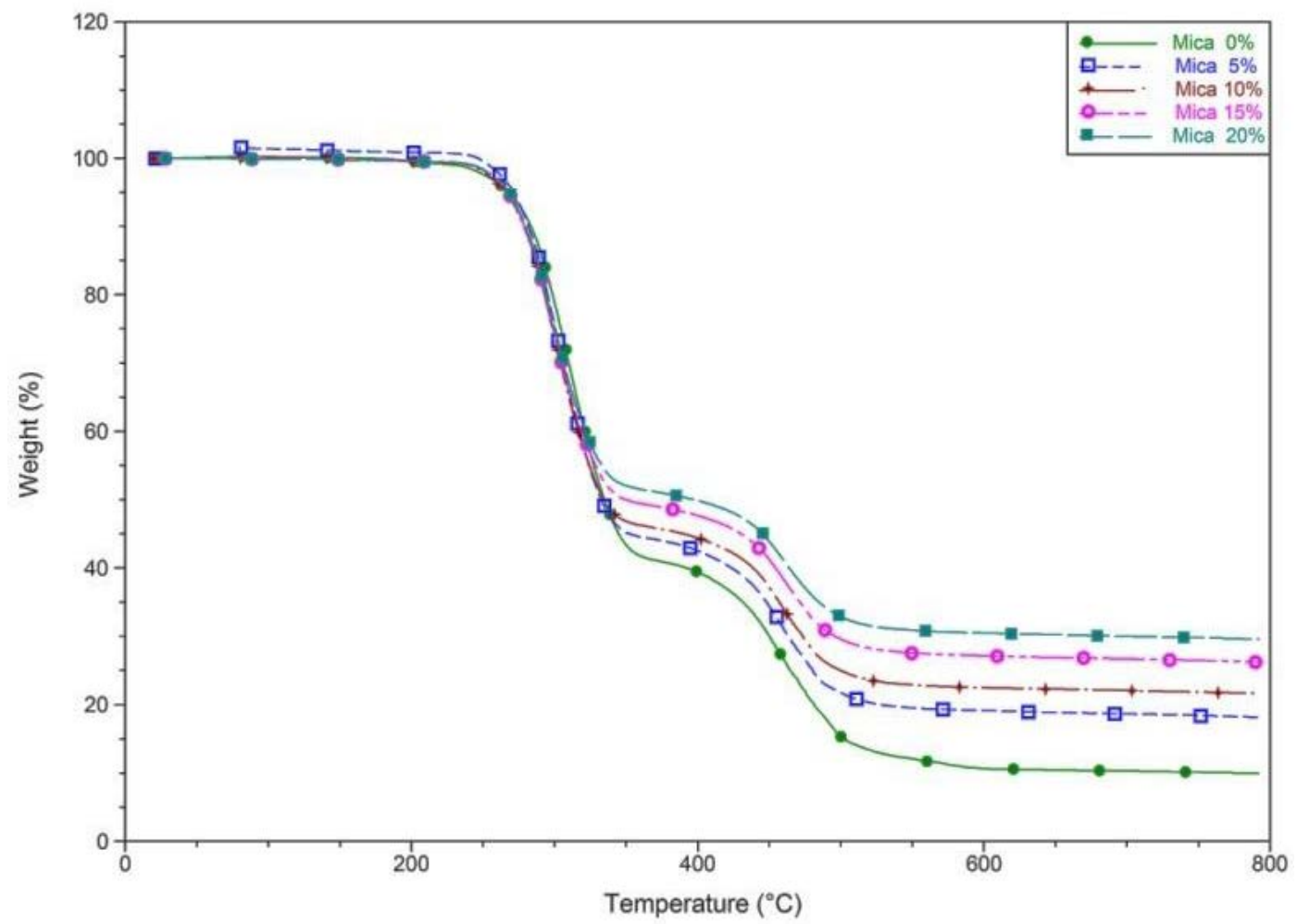

Figure 13: TGA analysis of PVC-Mica foam composites, the curves are labeled with respect to the value of residual weight at $800{ }^{\circ} \mathrm{C}$ from the top to bottom

Table 10: Primary and Secondary Decomposition Temperature of PVC-Mica foam composites

\begin{tabular}{|c|c|c|}
\hline $\begin{array}{r}\text { Mica } \\
\text { Wt. } \%\end{array}$ & $\begin{array}{r}\text { Primary Decomposition } \\
\text { Temperature }\left({ }^{\circ} \mathbf{C}\right)\end{array}$ & $\begin{array}{c}\text { Secondary Decomposition } \\
\text { Temperature }\left({ }^{\circ} \mathbf{C}\right)\end{array}$ \\
\hline 0 & 279.4 & 442.3 \\
\hline 5 & 273.8 & 442.8 \\
\hline 10 & 271.8 & 443.6 \\
\hline 15 & 271.2 & 445.2 \\
\hline 20 & 270.7 & 444.4 \\
\hline
\end{tabular}


Thermo mechanical properties of the PVC-Mica composites were determined by DMA analysis. Variations with temperature in the storage modulus (E'), which represents the elastic behavior of the composites, and the loss modulus (E"), which represents the viscous behavior, are shown in Figures 14 and 15, respectively. The magnitude of $E^{\prime}$ and the peak intensity of E" increase with the addition of mica up to $15 \%$. This may be attributed to the enhancement in the energy dissipation ability in the presence of solid filler in the polymer matrix and the increase in the polymerfiller and filler-filler slippages at the $\mathrm{T}_{\mathrm{g}}[28,29]$. However, in samples reinforced with $20 \%$ mica, the magnitude of $\mathrm{E}^{\prime}$ decreases; this may be attributed to the agglomeration of mica at higher concentrations. The agglomeration of mica may lead to higher friction between the particles and less interaction between the reinforcing phase and the host matrix, which may consequently reduce the energy dissipation in the reinforced polymer matrix [30].

In comparison to all the samples, a significant change in the elastic and viscous properties was observed in samples reinforced with 15\% mica with respect to the pristine PVC foam sample. The storage modulus was found toincrease from $\sim 225 \mathrm{MPa}$ to $\sim 480 \mathrm{MPa}$ at room temperature while the loss modulus (E") had increased from $\sim 60 \mathrm{MPa}$ to $\sim 88 \mathrm{MPa}$ around the glass transition temperature of the samples. This indicates that the visco-elastic properties of the PVC foam composites improve as the amount of mica is increased up to $15 \%$ in the composites and a further increase beyond this loading is detrimental. One can speculate that particle agglomeration at higher loadings may be one of the reasons 
which might hinder the effect of the reinforcing filler to further improve the viscoelastic properties.

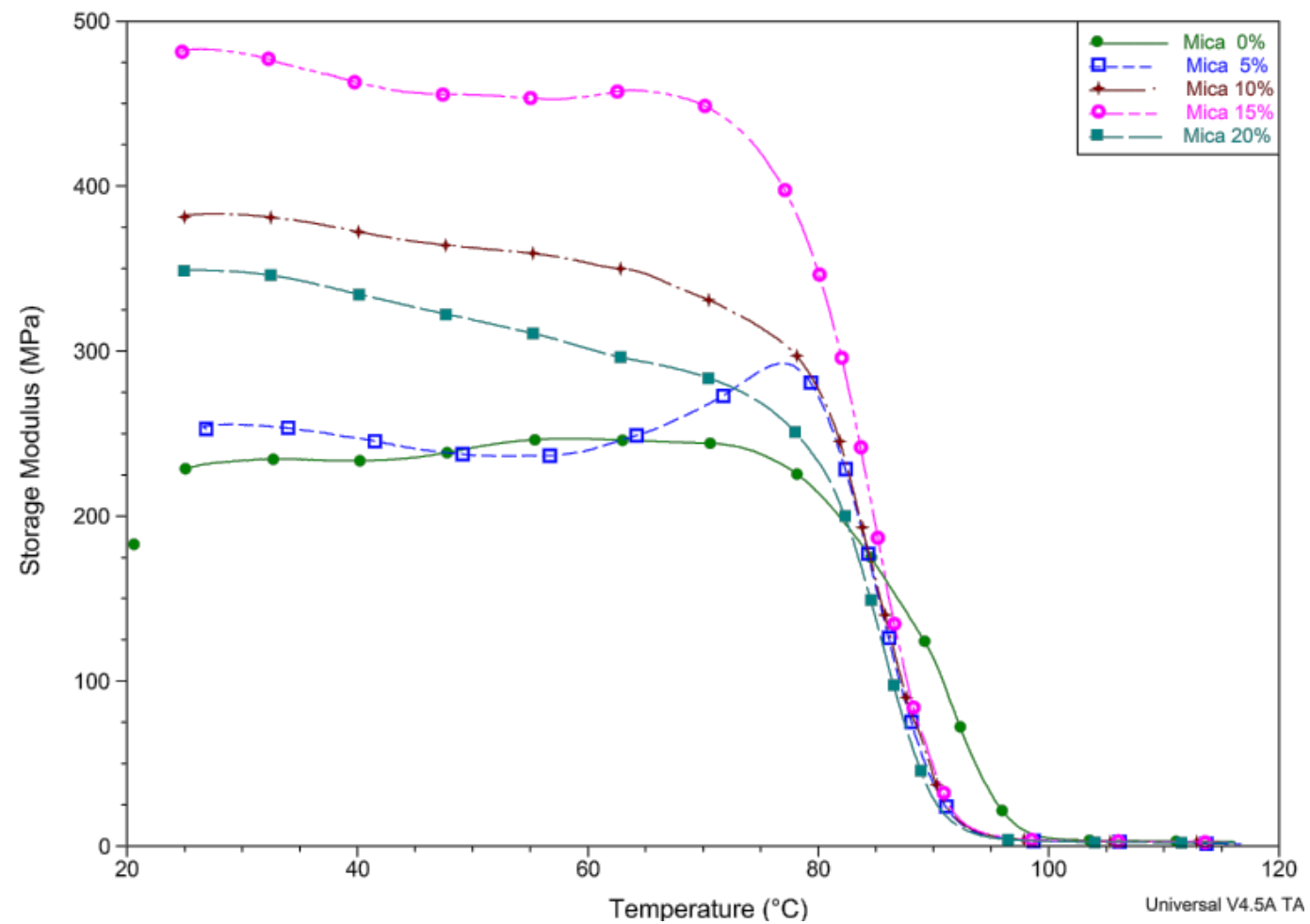

Figure 14: Storage Modulus (E') of PVC-Mica foam composites 


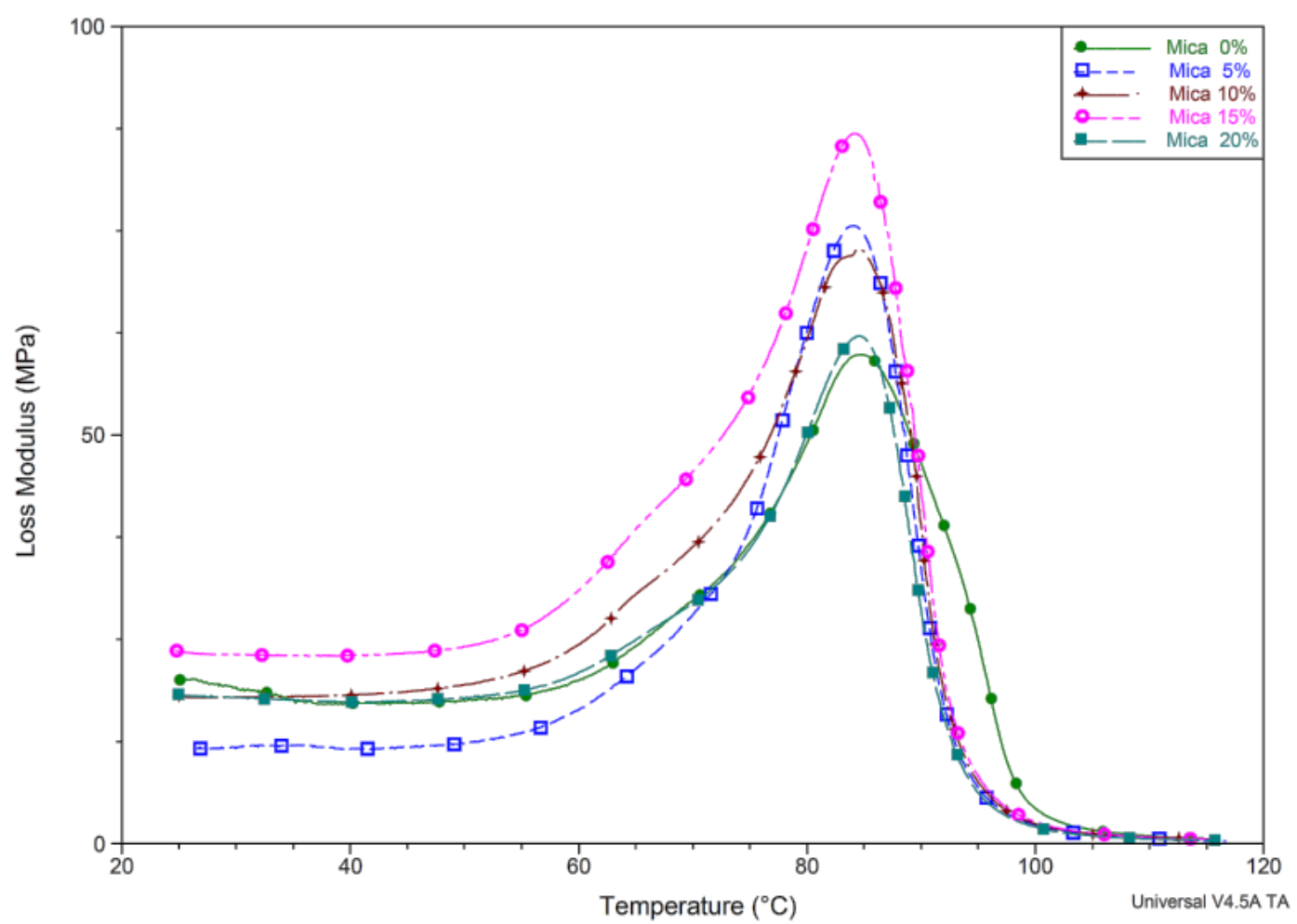

Figure 15: Loss Modulus (E") of PVC-Mica foam composites

\subsubsection{Mechanical Properties}

The effect of mica on the ultimate tensile strength (UTS) of the composite foams is shown in Figure 16. Composite samples reinforced with 10\% mica showed the highest UTS value of all the composites and the UTS started to decrease beyond this loading. The improvement in the UTS of the composites in comparison to the pristine polymer may be attributed to higher dispersion of mica platelets in the cell walls at lower concentrations and the good bonding between the platelets and the polymer matrix $[11,13,15]$. However, at higher concentrations of mica, i.e. above 15\%, the brittleness of the mica flakes combined with higher agglomeration in the cell walls may have led to a decrease in the overall strength of the composite foams. 


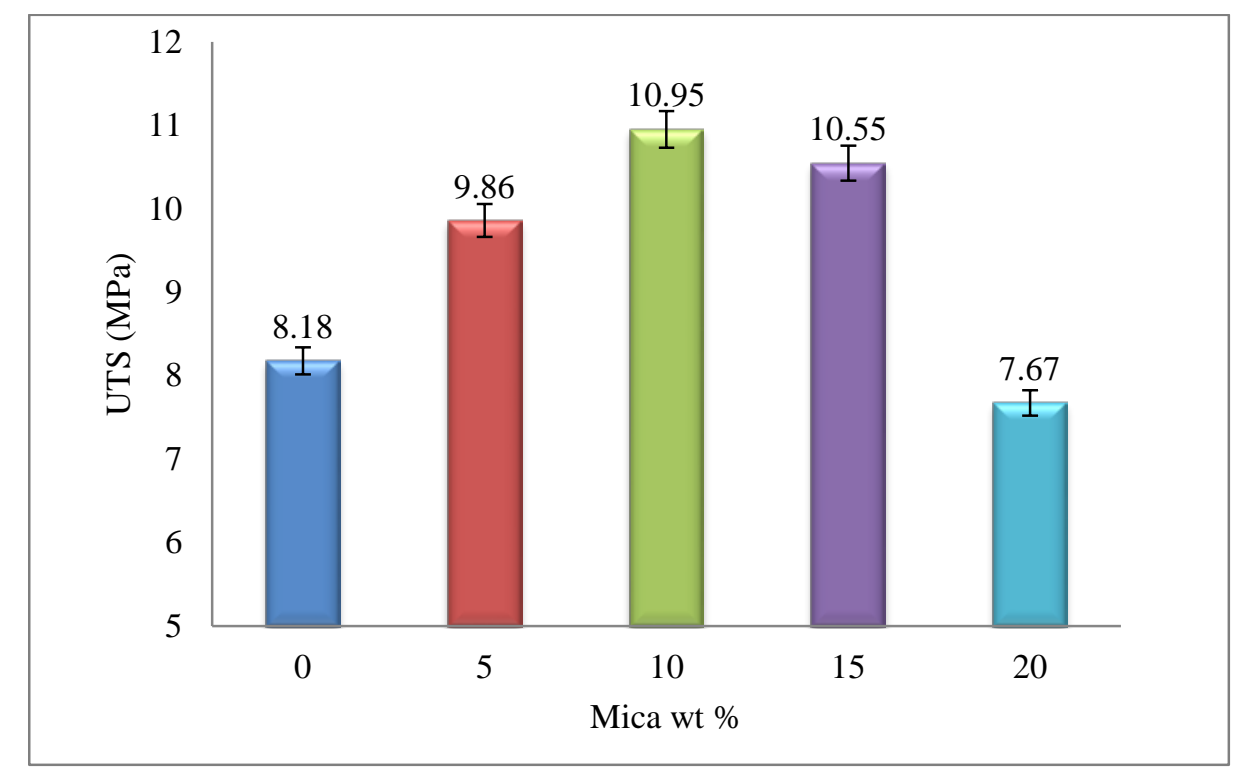

Figure 16: Ultimate Tensile Strength (UTS) of PVC-Mica foam composites

The ductility of the PVC-Mica composites, measured by the extension at break, is shown in Figure 17. The effect of mica on the ductility of the composite foams follows the same pattern and is similar to its effect on the tensile strength of the foams. The maximum ductility was observed in samples reinforced with $10 \%$ mica, whereas the ductility started to decrease at higher mica concentrations. The reinforcement of cell walls with mica provides additional strength and ductility under loading, thus delaying the rupture of the cell walls. This may be due to the lamellar structure of the mica flakes combined with the preferred orientation of the flakes along the cell walls, which improves the surface bonding with the polymer matrix $[11,13,15]$. The maximum improvement observed in samples with lower mica content may be due to the higher dispersion of the mica flakes in the cell walls which may have resulted in better surface bonding with the polymer phase. 
However, at higher concentrations of mica, the particles may have started to agglomerate in the cell walls and formed a separate solid phase which might have lowered the surface bonding with the polymer phase. Consequently, this might have lowered the strength and ductility of the composites at the cell walls causing them to rupture.

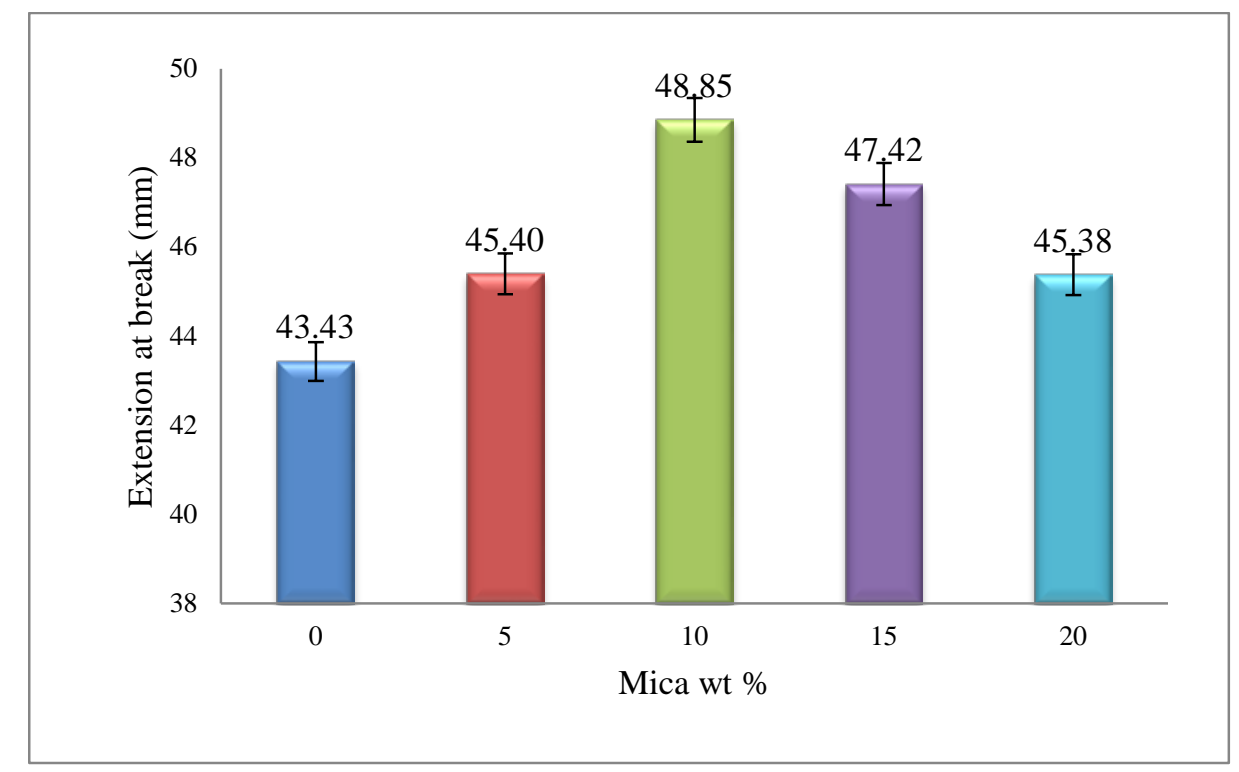

Figure 17: Ductility of PVC-Mica foam composites

Other mechanical properties of the PVC-Mica composites, such as compressive, flexural, and impact strengths, are summarized in Table 12. It can be noticed that the overall change in compressive strength of the composites was insignificant. This can be attributed to the orientation of micas' platelets, as mentioned above, along with the direction of the uniaxial compressive load, where this limits the load distribution and raises the brittle effect of the reinforcing phase. This can be seen clearly with increasing the content of the reinforcing phase to $20 \%$, in addition to the effect of the agglomeration of mica platelets. Also from 
Table 11, it can be noted that the presence of mica does not seem to improve the flexural strength of the composites. This can be attributed to the orientation of the mica flakes along the cell walls, which improves the strength of the composites up to a certain extent under tension, but has a detrimental effect on the strength of the composites under compression loading, which could indicate a localized loading failure. Since the test samples under flexure loading experience tensile stresses, as well as compression stresses on opposite sides, the net improvement of mica on the overall flexural strength is insignificant [13]. The impact strength of the PVC-Mica composites started to deteriorate with the addition of mica. This may be attributed to the increased rigidity of the polymer matrix, which is amplified at higher concentrations due to particles' agglomeration, which promotes brittle fracture under impact loading [15, 26, 33].

Table 11: Mechanical properties of PVC-Mica foam composites*

\begin{tabular}{|c|c|c|c|c|c|}
\hline $\begin{array}{c}\text { Mica } \\
\text { Wt. \% }\end{array}$ & $\begin{array}{c}\text { UTS } \\
\mathbf{( M P a )}\end{array}$ & $\begin{array}{c}\text { Extension at } \\
\text { Break (mm) }\end{array}$ & $\begin{array}{c}\text { Compressive } \\
\text { Strength } \\
\mathbf{( M P a )}\end{array}$ & $\begin{array}{c}\text { Flexural } \\
\text { Strength } \\
\mathbf{( M P a )}\end{array}$ & $\begin{array}{c}\text { Impact } \\
\text { Strength } \\
\mathbf{( J / \mathbf { m } ^ { 2 } )}\end{array}$ \\
\hline 0 & 8.17 & 43.43 & 12.07 & 17.26 & 30.13 \\
\hline 5 & 9.86 & 45.39 & 9.33 & 17.01 & 30.11 \\
\hline 10 & 10.95 & 48.85 & 12.61 & 17.25 & 29.56 \\
\hline 15 & 10.54 & 47.41 & 12.02 & 17.33 & 26.07 \\
\hline 20 & 7.67 & 45.38 & 11.03 & 17.19 & 22.06 \\
\hline
\end{tabular}

*The values of standard deviation are as below

\begin{tabular}{|c|c|c|c|c|}
\hline UTS & $\begin{array}{c}\text { Extension } \\
\text { at Break }\end{array}$ & $\begin{array}{c}\text { Compressive } \\
\text { Strength }\end{array}$ & $\begin{array}{c}\text { Flexural } \\
\text { Strength }\end{array}$ & $\begin{array}{c}\text { Impact } \\
\text { Strength }\end{array}$ \\
\hline 1.45 & 2.09 & 1.30 & 0.12 & 3.52 \\
\hline
\end{tabular}




\subsubsection{Microstructural Properties}

The dispersion and surface bonding of the reinforcing solid phase with the polymer matrix affects many important characteristics such as mechanical properties and dimensional stability $[15,26]$. Therefore, it is important to review the reinforcing phase-matrix interface and the distribution of the solid phase within the matrix in order to explain the characteristics and behavior of these composites. SEM micrographs of pristine PVC foam and the PVC foam composites reinforced with mica are shown in Figures 18(a-e).

The micrograph of the sample reinforced with 5\% mica shows good dispersion of mica in the PVC foam matrix (Figure 18b). In addition, one can also observe the lamellar structure of mica and its orientation parallel to the cell walls within the foam matrix. This is an indication of good bonding between the mica platelets and the PVC foam matrix, which explains partially the improvements in dimensional stability and mechanical properties of the composites. The micrographs also show that the dispersion of mica in the foam matrix was random up to a loading of $15 \%$, and the orientation of mica was mostly parallel within the cell walls. However, in samples containing 20\% mica (Figure 18e), some of the mica platelets seem to have agglomerated in the foam walls. This supports the discussion on the anomaly observed in the visco-elastic and mechanical properties of the PVC-mica foam composites. 




Figure 18: SEM micrographs of PVC-Mica foam composites at: (a) $0 \%$ (b) $5 \%$ (c) $10 \%$ (d) $15 \%$ and (e) $20 \%$ mica 


\section{CHAPTER 5}

\section{A COMBINATION OF E-GLASS FIBERS AND PHLOGOPITE MICA}

\subsection{PVC-GM FOAM COMPOSITES FORMULATION}

During the fabrication of PVC-Glass Fibers and Mica(GM) foam composite materials, besides the matrix and the reinforcing phase, additional components(stabilizers, foam blowing agents, and other additives) were added to make the foam composites, see Table 12.

Table 12: Composition of PVC-Glass Fiber and Mica (GM) foam composites

\begin{tabular}{|c|c|c|c|c|c|c|c|}
\hline \multirow{2}{*}{$\begin{array}{c}\text { Trade } \\
\text { code }\end{array}$} & $\begin{array}{c}\text { Glass } \\
\text { Fiber }\end{array}$ & Mica & $\begin{array}{c}\text { PVC } \\
\text { Resin }\end{array}$ & Stabilizer & $\begin{array}{c}\text { Blowing } \\
\text { Agents }\end{array}$ & Lubricants & $\begin{array}{c}\text { Processing } \\
\text { Aids }\end{array}$ \\
\cline { 1 - 4 } G0M0 & 0 & 0 & 92.5 & \multicolumn{2}{|c|}{ Content (wt. \%) } \\
\hline G5M5 & 5 & 5 & 82.5 & \multirow{2}{*}{0.85} & 0.5 & \multirow{2}{*}{0.6} & \multirow{2}{*}{6} \\
\hline G10M10 & 10 & 10 & 72.5 & & \\
\hline G15M5 & 15 & 5 & 72.5 & & & \\
\hline G5M15 & 5 & 15 & 72.5 & & & \\
\hline
\end{tabular}




\subsection{RESULTS AND DISCUSSION}

\subsubsection{Thermal Properties}

Dimensional stability of the foam composites was assessed as a percentage of linear shrinkage of the extruded foam composites when heated to $82{ }^{\circ} \mathrm{C}$ for 30 minutes, as shown in Figure 19. It is evident that increasing the percentage of glass fibers and mica reduces the thermal shrinkage of the PVC-GM foam composites from an initial value of $3.4 \%$ to $1.7 \%$ in G15M5 samples which were reinforced with 15\% GF and 5\% mica. This improvement accounts for a net reduction of 50\%. Since both of the mica and glass fibers have lower thermal expansion coefficient than PVC, increasing the total filler content leads to a good improvement in the dimensional stability of the composites. Additionally, in G5M5 and G10M10 samples, the shrinkage decreased by $20 \%$ and $45 \%$ when a total of $10 \%$ and $20 \%$ mixture of mica and GFs were added, respectively.The effect of each reinforcing material at fixed overall filler content (e.g. 20\%) can be observed by comparing G15M5 and G5M15. The shrinkage in these samples was reduced by $50 \%$ and $45 \%$, respectively. The interaction between mica platelets and the foam matrix seems to be more localized in comparison to the glass fibers. Glass fibers seem to have more interlocking sites with the foam cells along the fibers' length as shown in Figure 26. It is expected that adding a combination of glass fibers and mica (GM) totaling above $20 \%$ in the composites can further reduce the shrinkage due to the high dimensional and thermal stability of mica and glass fibers themselves [6, 7]. 
Although the attained improvements in dimensional stability of the composites were evaluated by a short-term shrinkage test, it is expected that the dimensional stability in case of long-term shrinkage will improve as well. This could be explained based on the effect of the bonding between the reinforcing phase and the matrix; this restricts the mobility of polymer chains [35], which consequently enhances the durability of the composites.The restriction of the polymer chains increases with increasing the interfacial surface between the glass fibers/mica's platelets and the matrix. In addition, adding mica can hinder the thermal degradation by decreasing the total diffusivity of oxygen and volatiles formed in the matrix. Moreover, the amount of UV is reduced in the composites due to the opaqueness property of Phlogopite mica.

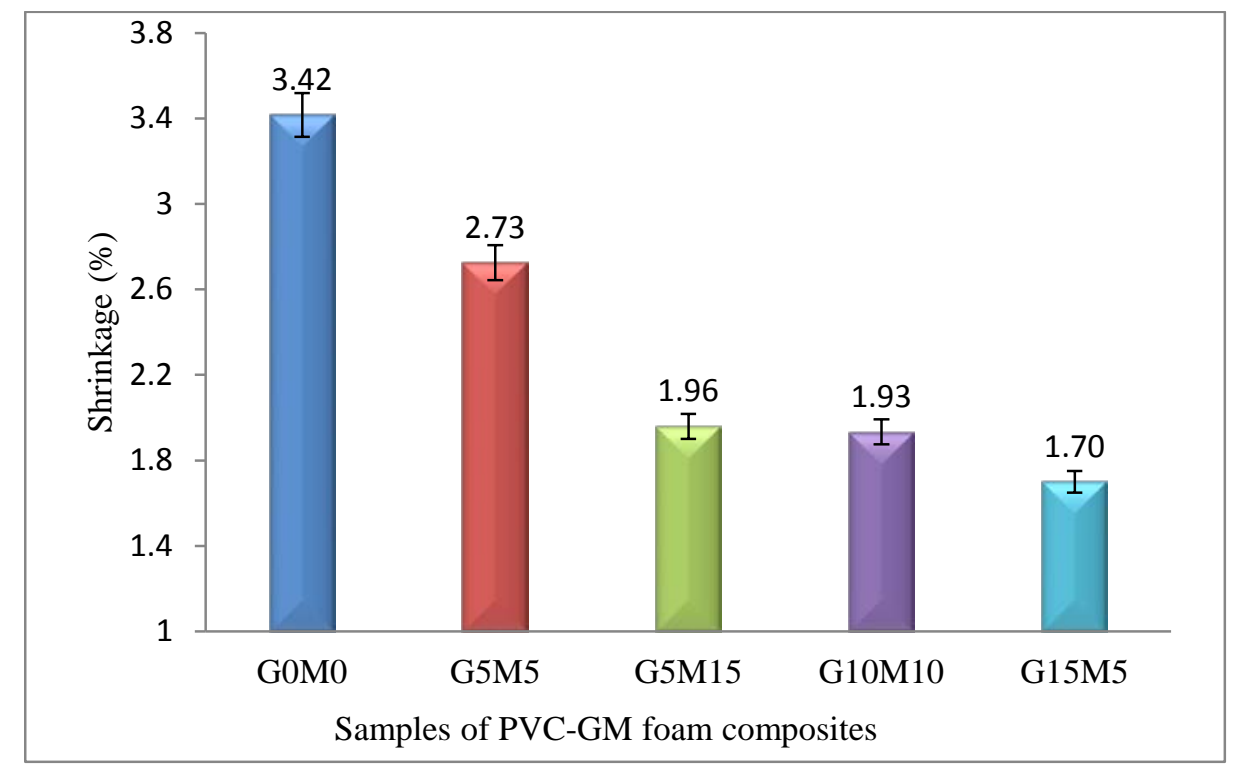

Figure 19: Dimensional stability of PVC-GM foam composites 
Heat resistance was evaluated qualitatively by visual inspection for surface flaws and shape distortion of the extruded samples after a heating and cooling cycle. Although the test samples did not show any flakes or cracks on the surface, some distortion was observed on the edges, as shown in Figure 20.

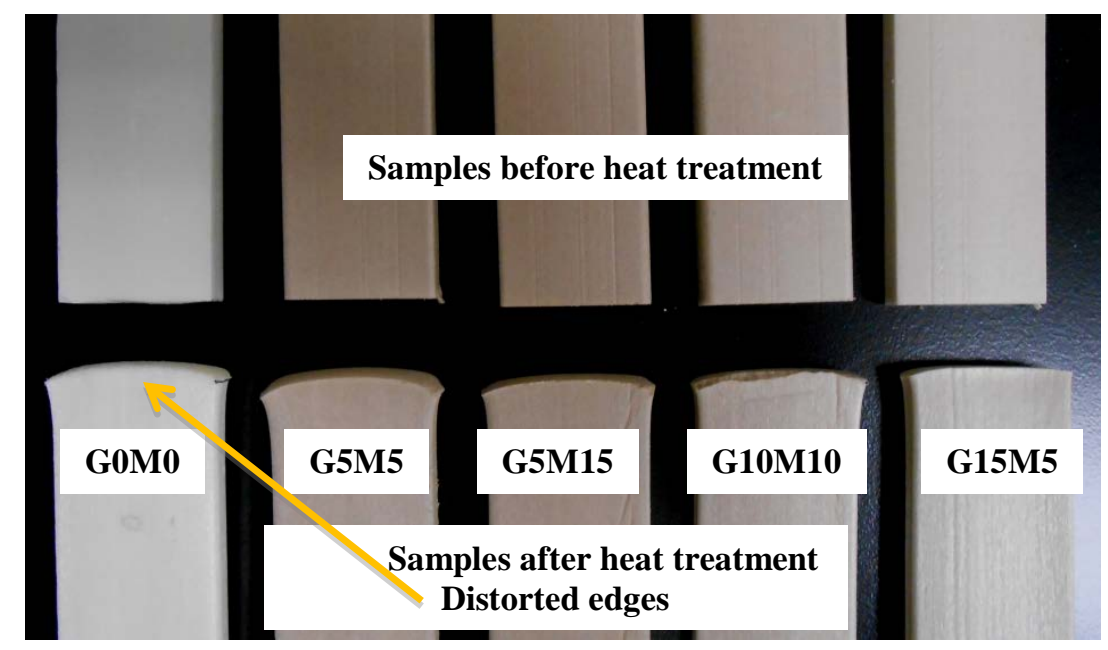

Figure 20:Distortion in PVC-GM foam composites before and after heat treatment.

Increasing the amount of GM in the composites decreased the shape distortion due to the high thermal resistance of both glass fiber and mica. However, the addition of GM did not seem to affect the glass transition temperature $\left(\mathrm{T}_{\mathrm{g}}\right)$ of the composites as was determined by DSC analysis. The $\mathrm{T}_{\mathrm{g}}$ remained around $82^{\circ} \mathrm{C}$ as is shown in Table 13.

Table 13: Glass transition temperatures of PVC-GM foam composites determined by DSC

\begin{tabular}{|c|c|c|c|c|c|}
\hline Sample & G0M0 & G5M5 & G10M10 & G5M15 & G15M5 \\
\hline $\boldsymbol{T}_{\boldsymbol{g}}\left({ }^{\circ} \mathbf{C}\right)$ & 82.2 & 82.1 & 82.7 & 83.36 & 81.78 \\
\hline
\end{tabular}


The results from TGA analysis of PVC-GM foam composites are presented in Figure 21. The average Primary Degradation Temperature (PDT) of the foam composites begins around $272{ }^{\circ} \mathrm{C}$, while the average Secondary Degradation Temperature (SDT) is around $443{ }^{\circ} \mathrm{C}$. As shown in Table 14, increasing the amount of GM increases the SDT of the composites, which means that it takes more energy to break the hydrocarbon backbone of the polymer matrix $[27,28]$. On the other hand, PDT of the composites, which indicates the decomposition of chlorine from the polymer chains, decreases by increasing GM content. This can be attributed to the higher thermal conductivity of mica and glass fiber, which results in faster heat transfer into the PVC matrix, thus lowering the thermal degradation temperatures. The residual weight at $800^{\circ} \mathrm{C}$ was found to increase as the amount of GM increased in the composites due to the presence of higher amounts of the inorganic fillers in the matrix [28]. 


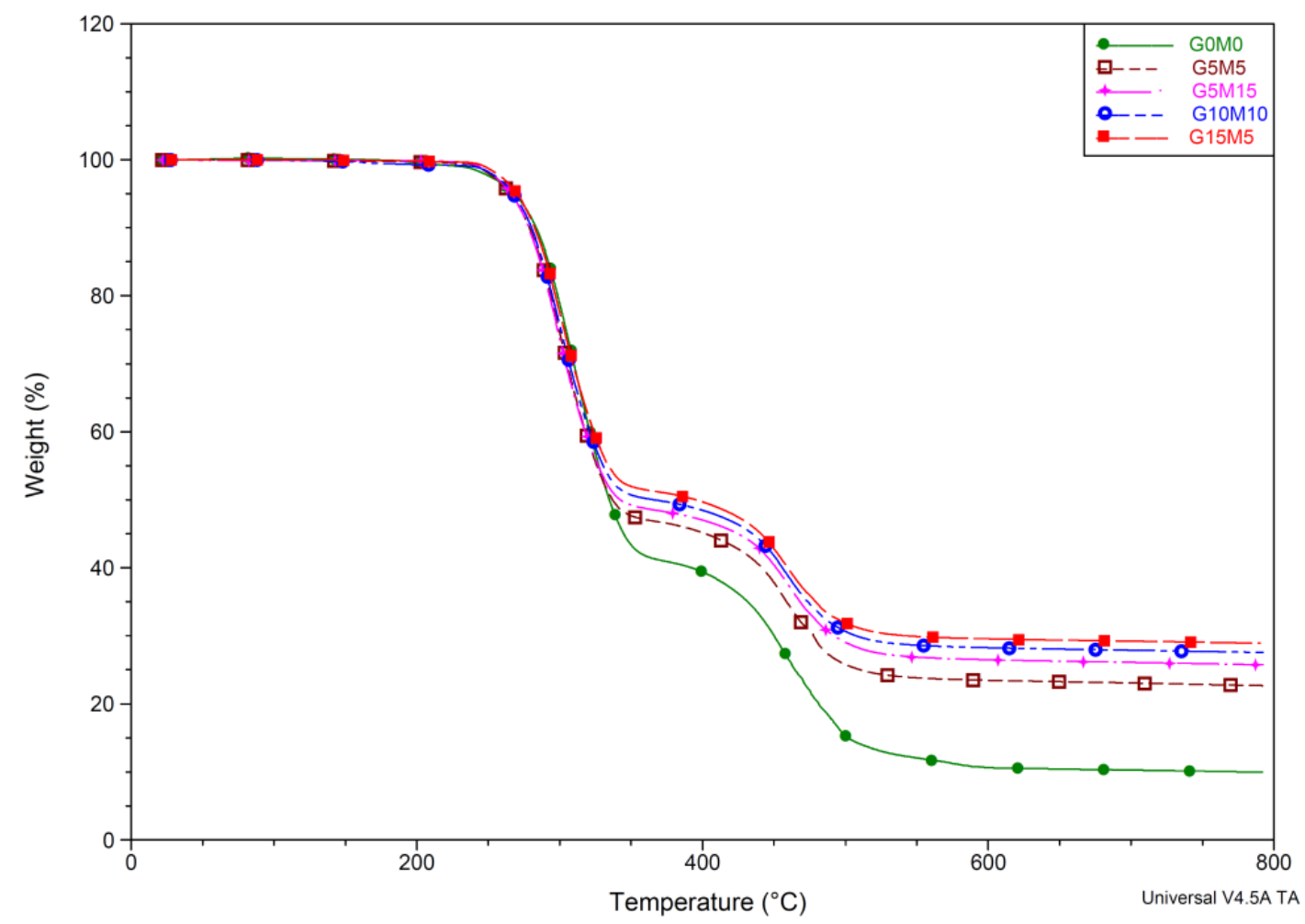

Figure 21: TGA analysis of PVC-GM foam composites, the curves are labeled with respect to the value of residual weight at $800{ }^{\circ} \mathrm{C}$ from the top to bottom

Table 14: Primary and Secondary Decomposition Temperature of PVC-GM foam composites

\begin{tabular}{|c|c|c|}
\hline Sample & $\begin{array}{c}\text { Primary Decomposition } \\
\text { Temperature }\left({ }^{\circ} \mathbf{C}\right)\end{array}$ & $\begin{array}{c}\text { Secondary Decomposition } \\
\text { Temperature }\left({ }^{\circ} \mathbf{C}\right)\end{array}$ \\
\hline G0M0 & 279.4 & 442.2 \\
\hline G5M5 & 271.2 & 442.7 \\
\hline G5M15 & 270.4 & 443.6 \\
\hline G10M10 & 273.2 & 444.3 \\
\hline G15M5 & 273.3 & 444.1 \\
\hline
\end{tabular}


Thermo mechanical properties of the PVC-GM foam composites were determined by DMA analysis. Variations with temperature in the storage modulus (E'), which represents the elastic behavior of the composites, and the loss modulus (E"), which represents the viscous behavior, are shown in Figures 22 and 23, respectively. The magnitude of E' and the peak intensity of E" increase with the total addition of GM, where all the samples of PVC-GM foam composites showed good to excellent improvement in elastic and viscous properties. This may be attributed to the enhancement in the energy dissipation ability in the presence of solid filler in the polymer matrix and the increase in the polymer-filler and fillerfiller slippages at the $T_{g}[28,29]$.

In comparison to all the samples, a significant change in the elastic and viscous properties were observed in G15M5 with respect to the pristine PVC foam sample; the storage modulus was found to increase significantly from 225 MPa to $\sim 720 \mathrm{MPa}$ at room temperature which represents $220 \%$, while the loss modulus (E") increased from $\sim 60 \mathrm{MPa}$ to $122 \mathrm{MPa}$ which represents 103\% around the glass transition temperature of the samples. This indicates that the visco-elastic properties of the PVC foam composites improve as the amount of GM is increased by adding $15 \%$ GF and 5\% mica in the composites, combined with good bonding between the reinforcing phases and the foam matrix. This can be attributed to the longitudinal form of glass fibers combined with the platy structure of mica and their orientation within the cell walls of the PVC foam matrix, as shown in Figures 26 (c, g). However, in G5M15 samples, the magnitude of E' decreases and this may be attributed to the agglomeration of mica at higher concentrations with 
lowamounts of GF, as shown in Figure 26(d), The agglomeration of mica may lead to higher friction between the particles and less interaction between the reinforcing phases and the host matrix, which may consequently reduce the energy dissipation in the reinforced polymer matrix [30]. One can speculate that particle agglomeration at higher loadings may hinder the effect of the reinforcing fillers to further improve the visco-elastic properties of the composites.

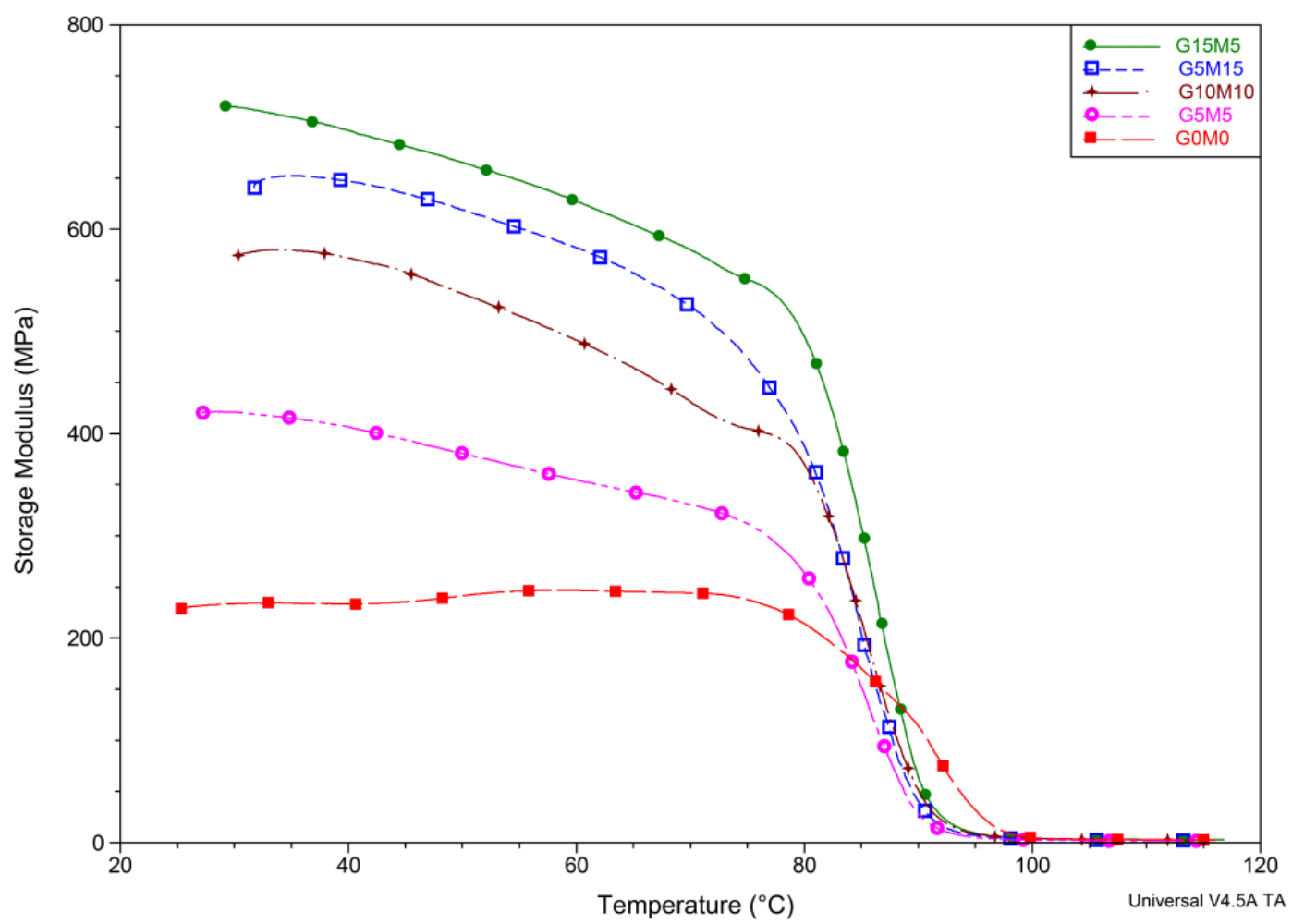

Figure 22: Storage Modulus (E') of PVC-GM foam composites 


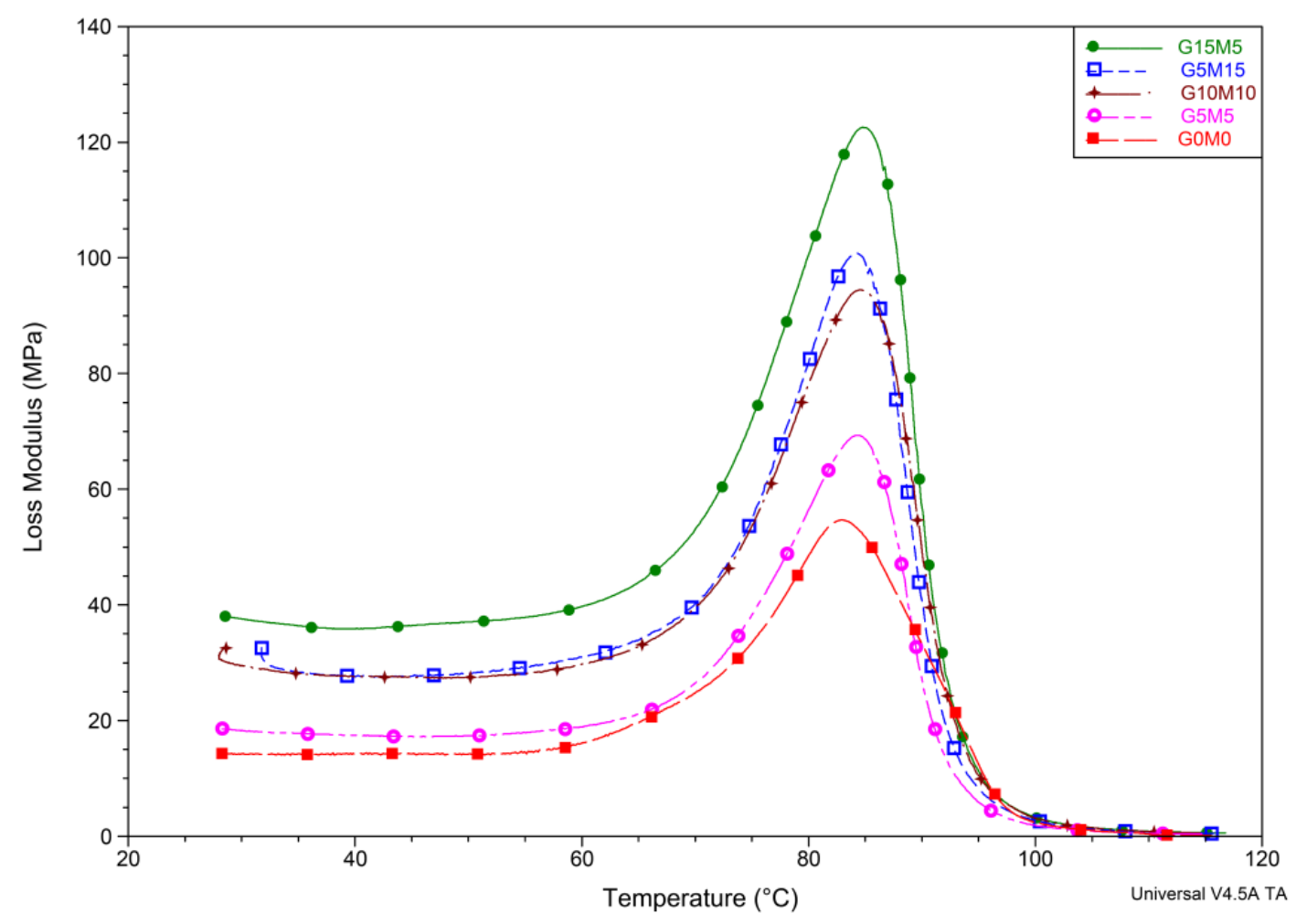

Figure 23:Loss Modulus (E") of PVC-GM foam composites

\subsubsection{Mechanical Properties}

The effect of GM on the ultimate tensile strength (UTS) of the composite foams is shown in Figure 24. Composite samples (G15M5) showed the highest UTS value among all the composites. The UTS increased from 8.17 MPa to 14.83 MPa which represents $\sim 82 \%$ increment. This may be attributed to the longer penetration of the glass fibers through the foam cell walls and a good dispersion and bonding between the mica platelets and the polymer matrix [19, 31, 32]. However, at higher mica and lower GF content, (e.g. G5M15), the brittleness of the mica flakes combined with higher agglomeration in the cell walls may have led to a decrease in the strength of the composite foams. Overall, the tensile strength of the 
PVC-GM foam composites improved by $44 \%$ to $82 \%$ with respect to the pristine sample (G0M0).

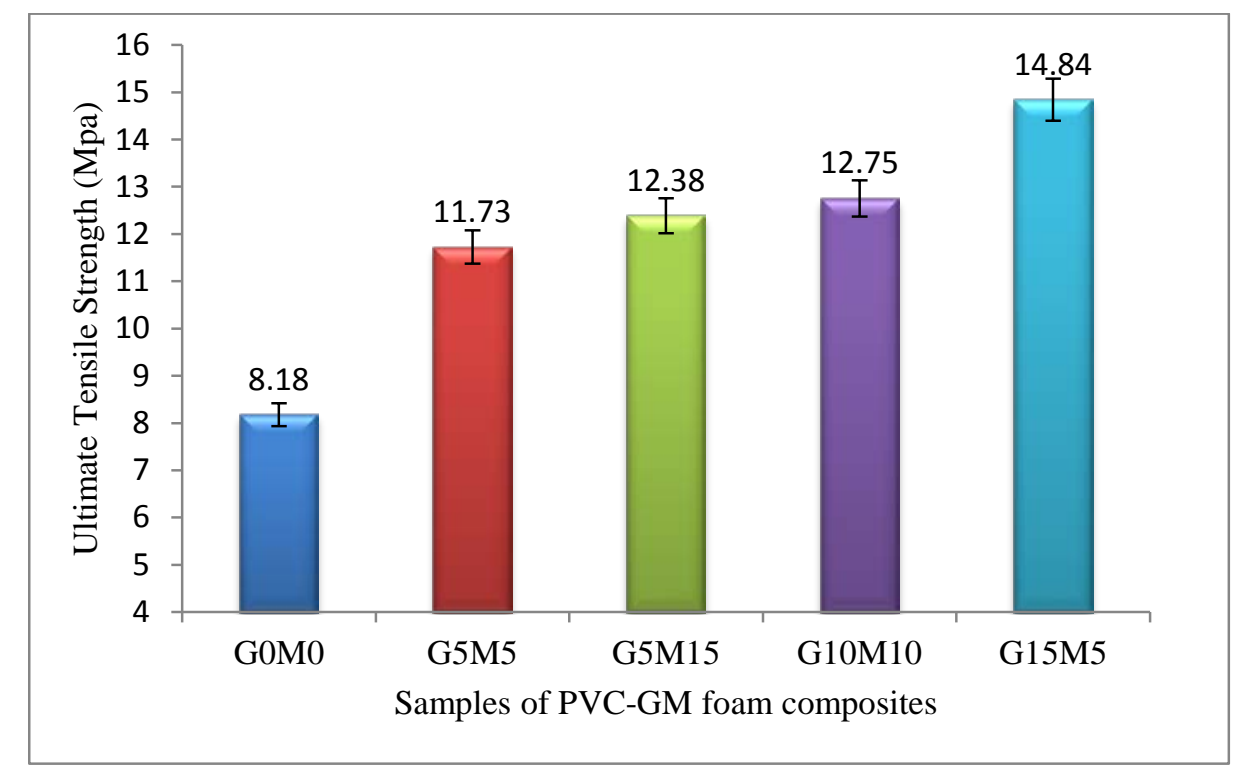

Figure 24: Ultimate Tensile Strength (UTS) of PVC-GM foam composites

The ductility of the PVC-GM composites was measured by the extension at break, as shown in Figure 25. The reinforcement of cell walls with GM provides additional strength and under loading. However, the effect of GMcontent on the ductility variesbetween the foam composites. The maximum ductility was observed in G5M5 and G5M15 samples due to the low concentration of long glass fibers in the composites. Long glass fibers have been shown to penetrate multiple cell walls and interlockingthem along the length of the fibers, which restricts the extension of the composites ${ }^{[24]}$. This also indicates strong bonding between the glass fibers surface and the PVC cell walls.The opposite is true at higher GF concentration, e.g. 10\% (G10M10) and 15\% (G15M5). The extension at break ranged between 29$31.5 \mathrm{~mm}$, significantly lower than the 42 mmobserved in samples reinforced with 5\% GFs,i.e., G5M5 and G5M15. As expected, the highest ductility was observed in 
the pristine polymer due to the higher continuity of polymer chains in the matrix and lower defect sites in the absence of solid phase fillers $[11,13,15]$.

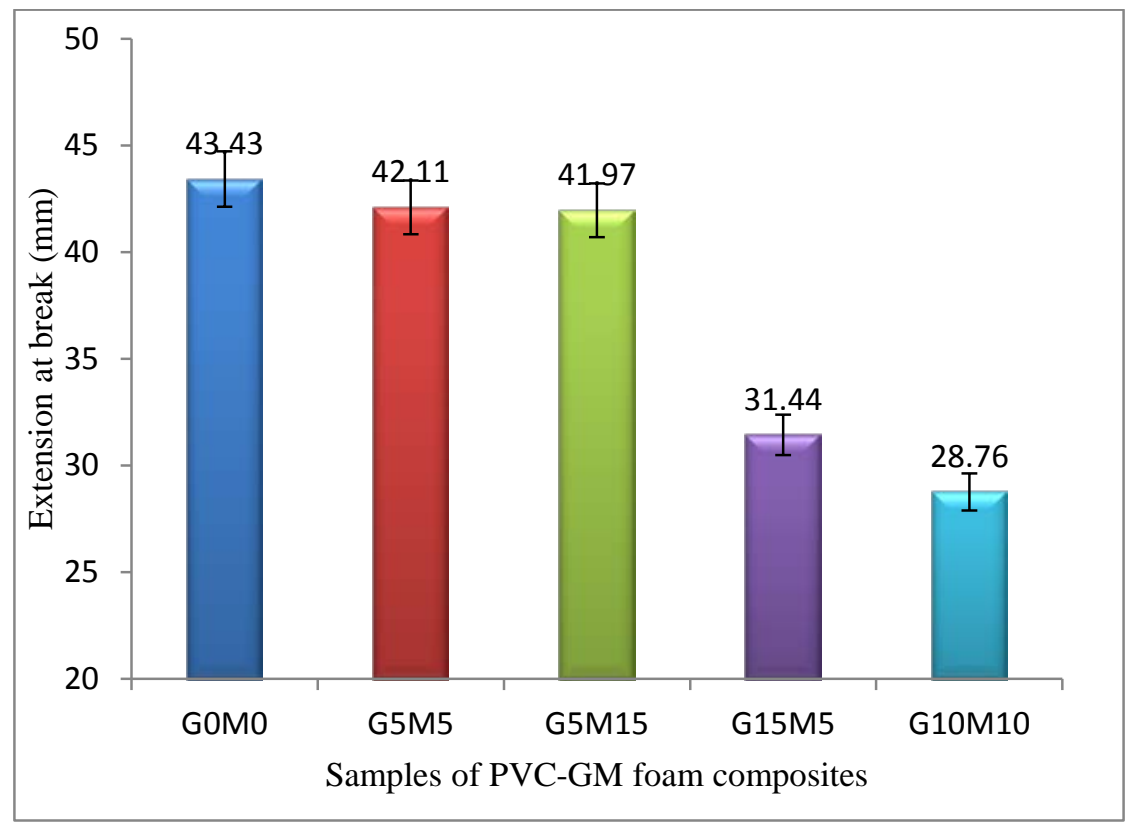

Figure 25: Ductility of PVC-GM foam composites

Other mechanical properties of the PVC-GM composites,such as compressive, flexural, and impact strengths, are summarized in Table 15. It can be observed that adding GM leads to improve the compressive strength. Where, the compressive strength of G5M5 composites improved by $~ 10 \%$, with respect to pristine samples, and increases to $\sim 32 \%$ by increasing the mica's content to $15 \%$. Whereas, increasing the GFs content to $15 \%$ leads to an improvement of $\sim 45 \%$. This can be attributed to the enhancement in the cell walls by adding mica and increasing the interlocking between the fibers and the matrix through multi-cell walls. Overall, this leads to better load distribution in the composites. Also, it can be noticed that the presence of GM seems to improve the flexural strength of the composites, due to the increment in UTS and compressive strength, with a higher 
impact of glass fibers as a result to their cell penetration and interlocking behavior as seen in the SEM micrographs. A comparison between G5M5 and G5M15 shows that increasing mica content at a constant GF level, flexural strength and impact strength increase by $1.32 \%$ and $14.82 \%$, respectively. Meanwhile,increasing the amount of GF with a fixed amount of mica in G5M5 and G15M5 samples improved the flexural strength and impact strength by $10.58 \%$ and $19.78 \%$, respectively. Among all samples, the highest flexural strength was observed in G15M5 with the highest GF content and lowest mica content. At higher GF loading, the impact strength is improved due the strengthening of the cells as was observed by the UTS and flexural strength values.The impact strength of the PVCGM composites started to deteriorate with the addition of GM compared to G0M0. This may be attributed to the increased rigidity of the polymer matrix at lowermica and GF concentrations, which promotes brittle fracture under impact loading [11, 13, 20, 33]. 
Table 15: Mechanical properties of PVC-GM foam composites*

\begin{tabular}{|c|c|c|c|c|c|}
\hline Samples & $\begin{array}{c}\text { UTS } \\
\text { (MPa) }\end{array}$ & $\begin{array}{c}\text { Extension } \\
\text { at Break } \\
\mathbf{( m m )}\end{array}$ & $\begin{array}{c}\text { Compressive } \\
\text { Strength } \\
\mathbf{( M P a )}\end{array}$ & $\begin{array}{c}\text { Flexural } \\
\text { Strength } \\
\mathbf{( M P a )}\end{array}$ & $\begin{array}{c}\text { Impact } \\
\text { Strength } \\
\mathbf{( J / \mathbf { m } ^ { 2 } )}\end{array}$ \\
\hline G0M0 & 8.17 & 43.43 & 12.07 & 17.26 & 30.13 \\
\hline G5M5 & 11.72 & 42.1 & 13.36 & 22.77 & 23.51 \\
\hline G5M15 & 12.38 & 41.96 & 15.95 & 23.07 & 26.99 \\
\hline G10M10 & 12.75 & 28.76 & 14.15 & 22.66 & 26.07 \\
\hline G15M5 & 14.83 & 31.43 & 17.51 & 25.18 & 28.16 \\
\hline
\end{tabular}

\subsubsection{Microstructural Properties}

The dispersion and surface bonding of the reinforcing solid phases, glass fibers and mica, with the polymer matrix affects many important characteristics, such as mechanical properties and dimensional stability [15-17, 21, 22]. Therefore, it is important to review the reinforcing phases-matrix interface and the distribution of the solid phase within the matrix in order to explain the characteristics and behavior of these composites. SEM micrographs of pristine PVC foam and the PVC-GM foam composites are shown in Figure 26(a-g).

* The values of standard deviation are as below
\begin{tabular}{|c|c|c|c|c|}
\hline UTS & $\begin{array}{c}\text { Extension } \\
\text { at Break }\end{array}$ & $\begin{array}{c}\text { Compressive } \\
\text { Strength }\end{array}$ & $\begin{array}{c}\text { Flexural } \\
\text { Strength }\end{array}$ & $\begin{array}{c}\text { Impact } \\
\text { Strength }\end{array}$ \\
\hline 2.42 & 6.88 & 2.15 & 2.94 & 2.46 \\
\hline
\end{tabular}



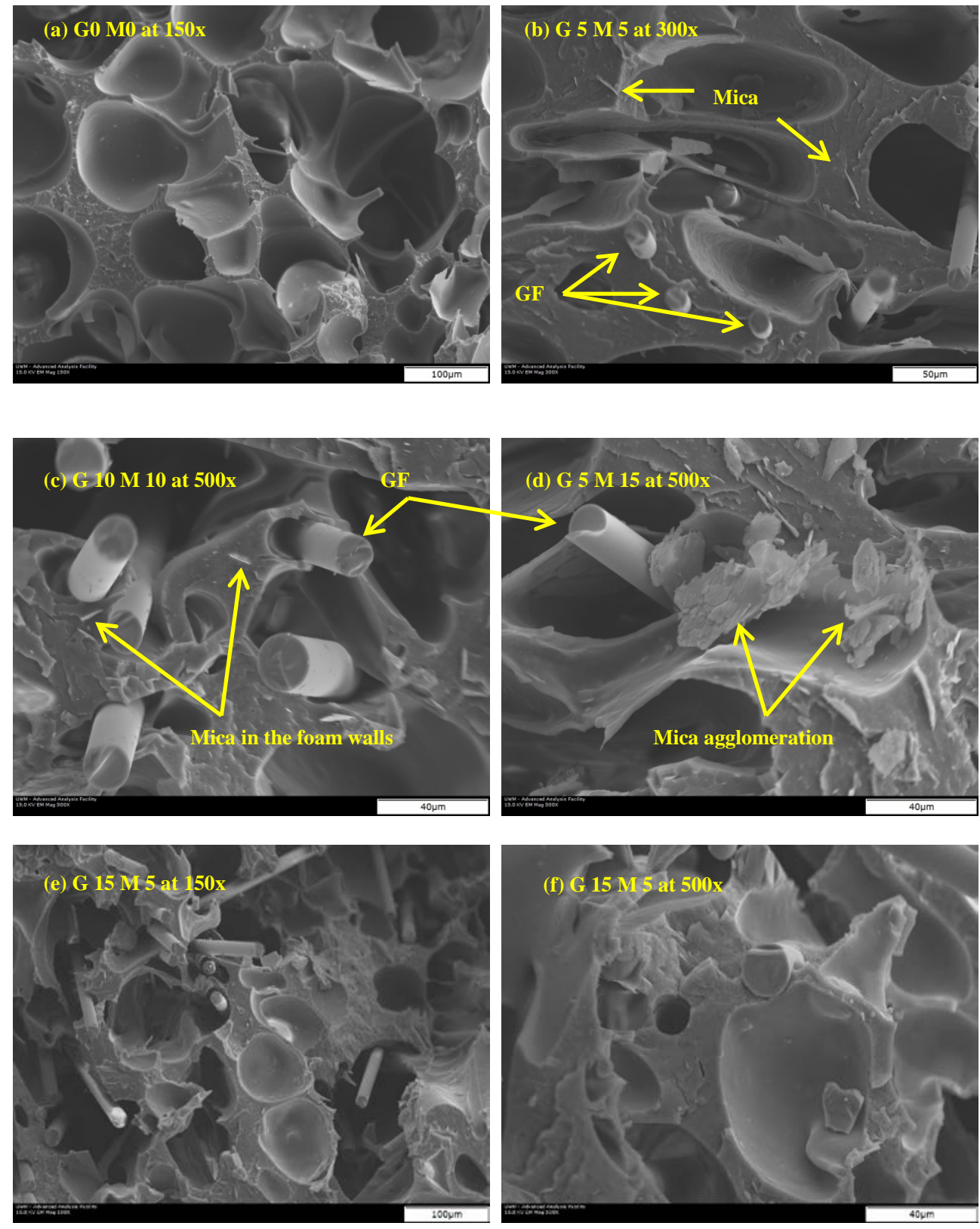


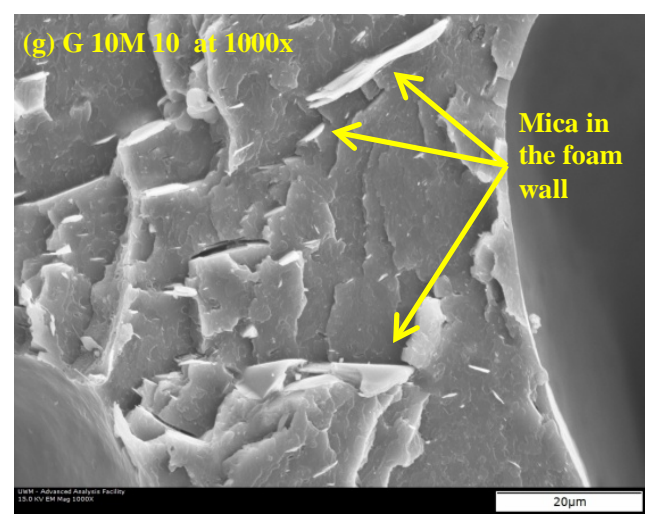

Figure 26: SEM micrographs of PVC-GM foam composites: (a) G0M0 at 150x (b) G5M5 at 300x(c) G10M10 at 500x (d) G5M15 at 500x (e) G15M5 at 150x (f) G $15 M 5$ at 500x and $(\mathrm{g})$ G10M10 at 1000x

The cell size and shape of pure PVC foam is shown in Figure 26a. Figures 26b-26gshowthe distribution and the orientation of mica and GFs in the PVC foam matrix. It is clear from the SEM micrographs that the distribution of GFs is random in the foam matrix and the GFs penetrate through the foam walls and across the cells of the PVC foam. On the other hand, the platelets of mica are embedded within the foam walls and are dispersed randomly in the foam matrix; samples reinforced with higher amounts of mica (G5M15) show some agglomeration as seen in Figure 26d.

The microstructure of the composite sample G15M5, which exhibited superior dimensional, thermal and mechanical properties, is shown in Figure 26e, the fracture surface of this sample at a higher magnification $(500 \mathrm{x})$ is shown in Figure 26f. Examination of the microstructures of this sample leads to the assumption that the orientation of the GF's through the foam matrix is best suited 
to dissipate the energy within the composite which might have led to superior visco-elastic properties of the composite in comparison to others. In addition, the fracture surface shows that the fiber-matrix interface and the overall bonding between the reinforcing phases and the foam matrix was optimum and better suited to enhance the properties of the composite.

Figure 26 (g), shows the microstructure of the fracture surface of the sample G10M10, focusing on a region rich in mica. One can observe the lamellar structure of mica embedded intact within the foam matrix even after fracture. This is an indication of good bonding between the mica platelets and the PVC foam matrix, which explains partially the improvements in dimensional stability and mechanical properties of the composites. 


\section{CHAPTER 6}

\section{CONCLUSIONS}

\subsection{PVC- GLASS FIBERS FOAM COMPOSITES}

Dimensional stability of PVC-GF foam composites measured by thermal shrinkage and heat resistance was improved significantly with the addition of glass fibers to the foam composites. Thermal shrinkage decreased for both fibers length $1 / 32$ " and $1 / 16$ "by $60 \%$ and $65 \%$, respectively, with visible improvements to the shape distortion. Longer glass fibers yielded better improvement than shorter fibers due to their higher interlocking with the foam cells. SEM images of the foam cells confirmed the random distribution and orientation of the glass fibers in the polymer matrix; the connections between the GFs and the matrix are only through the walls of the foam-matrix. Also, SEM images confirmed that longer glass fibers exhibit higher crossings through the composite walls, and more interlocking between the fibers themselves.

Mechanical properties of the PVC-GF composites have mixed reactions. Whereas the tensile and flexural strengths seem to be marginally affected by the addition of glass fibers, the ductility and impact strengths decreased significantly with higher GF loadings. However, longer glass fibers scored better than their shorter counterparts due to higher interlocking between the fibers and the foam cells, which results in better load distribution in the matrix. The viscoelastic 
properties of the PVC-GF composites measured by storage modulus which was found to increase for both fibers length $1 / 32$ " and 1/16" by 150\% and 200\%, respectively.

\subsection{PVC- MICA FOAM COMPOSITES}

The lamellar structure of the mica flakes combined with their preferred orientation along the cell walls improved their surface bonding with the polymer matrix. This led to a significant improvement in the dimensional stability of the PVC composites by $44 \%$, and it was proportional to the concentration of mica in the composite. In addition, the viscoelastic properties of the composites, measured by the storage and loss moduli, were found to improve by $\sim 113 \%$ and $\sim 46 \%$, respectively,at a concentration of $15 \%$ mica, whereas the tensile strength and ductility were optimum at a concentration of $10 \%$ mica in the composites. These properties were found to deteriorate at higher concentrations of mica due to particle agglomeration in the cell walls. The addition of mica up to $20 \%$ in the composites did not change the flexural strength significantly, although it resulted in over $25 \%$ reduction in the impact strength.

SEM images of the cellular structure confirmed higher dispersion of the mica flakes at lower concentrations ( $<15 \%)$, and a tendency for agglomeration at higher concentrations (> 15\%). In addition SEM images confirmed the orientation of the mica flakes was parallel to the cell walls which resulted in better surface bonding with the polymer phase. However, at higher concentrations, the mica particles 
seemed to agglomerate in the cell walls forming separate brittle solid phases, which seemed to lower the surface bonding with the polymer phase.

\subsection{PVC-GLASS FIBERS AND MICA}

Dimensional stability of PVC-GM foam composites measured by thermal shrinkage and heat resistance was improved significantly with the addition of mica and glass fibers to the PVC foam composites. Thermal shrinkage decreased by almost 50\%, with visible improvements to the shape distortion in samples reinforced with 15\% GF and 5\% mica. In addition, the samples exhibited superior viscoelastic properties measured by the storage and loss moduli, which were found to improve by $\sim 220 \%$ and $\sim 103 \%$, respectively. The tensile strength of the composites was found toincreaseby $44 \%$ to $82 \%$. The flexural strength wasalso enhanced for all the samples, with the highest increase of $46 \%$ exhibited by the sample with the highest GF concentration. Meanwhile, the ductility decreasedsignificantly under high GF loading.

SEM images of the cellular foam structure confirmed good dispersion of glass fibers and mica flakes at lower concentrations of mica $(<15 \%)$, with a tendency for agglomeration when themica content was increased to $15 \%$ and the GF content was lowered to5\%. In addition, SEM images confirmed that the orientation of the mica flakes was parallel to the cell walls which resulted in better surface bonding with the polymer phase. Overall, the glass fibers seemed to have a higher impact on the properties of the PVC-GM composites. The length of the glass 
fibers were suitable for penetration through the foam cells which led to higher interlocking with the polymer matrix and might have contributed significantly to the improvements in the dimensional stability and mechanical behavior of the composites.

\subsection{FUTURE WORK}

In spite of the significant improvements that have been accomplished in this work by using the solid fillers (Glass Fibers and Mica) separately and simultaneously, there are a number of issues that have risen during this study which need further investigation. From these topics, studying the effect of solid fillers on cell formation and foaming process of extruded polymer foam, in order to have a better understanding of the bonding mechanism between the matrix and the solid phases, could lead to more improvements in the foam composite. 


\section{REFERENCES}

[1] Shen, L.; Haufe, J.; Patel, M. Product overview and market projection of emerging bio-based plastics. Report, Utrecht University, Netherlands, June 2009.

[2] Lee, S.; Park, C.; Ramesh, N. Polymeric Foams. Florida: Boca Raton, 2007.

[3] http://www.highbeam.com/doc/1G1-111617437.html(accessed on October 13, 2014)

[4] Jiang, H; Kamdem, D. P. Development of poly(vinyl chloride)/wood composites. A literature review. J Vinyl AdditTechnol. 2004, 10, 59-69.

[5] Ráthy, I.; Kuki, Á; Borda, J.; Deák, G.; Zsuga, M.;Marossy, K.; Kéki, S. Preparation and characterization of poly(vinyl chloride)-continuous carbon fiber composites. J. Appl. Polym. Sci.2012, 124, 190-194.

[6] http://www.lkabminerals.com/en/Minerals/Phlogopite-Mica/(accessed on October 2014).

[7] http://www.fibreglast.com/product/116_inch_Milled_Glass_Fibers_29/Fillers/(accessed on November 2014).

[8] Katz, H.;Mileski, H.Handbook of Fillers for Plastics. New York, 1987.

[9] White L, J. Principles of Polymer Engineering Rheology. USA, 1990.

[10] Young, R.; Lovell, P. Introduction to Polymers. Florida: Boca Raton, 2011.

[11] Liang J.; Yang Q. Mechanical, thermal, and flow properties of HDPE-mica composites. J. of Thermoplast. Compos.Mater. 2007, 20, 225-236.

[12] Souza D.; Andrade C.; Dias M. Effect of synthetic mica on the thermal properties of poly(lactic acid). J. Polímeros: Ciência e Tecnologia. 2014, 24, 20-24.

[13] Sreekanth M.; Bambole V.; Mhaske S, et al. Effect of Concentration of Mica on Properties of Polyester Thermoplastic Elastomer Composites. J. Min. Mat. Char. \& Eng. 2009, 8, 271282.

[14] Marshall C.; Rozett R.; Kunkle A. Effect of Mica as a filler in Polypropylene, HDPE, and PVC, Sess 8 SPI, Reinforced Plastics/Composites Inst, New York, NY, USA, 1985. 
[15] Deshmukh S.; Rao A.; Gaval V.; Mahanwar P. Mica-Filled PVC Composites: Effect of Particle Size, Filler Concentration, and Surface Treatment of the Filler, on Mechanical and Electrical Properties of the Composites. J. Thermoplast. Compos. Mater. 24, 583-599.

[16] Jang, S. H.; Kim, Y. H.; Lim, S.; Choi, G. D.; Kim, S. H.; Kim, W. N. Effects of fiber characteristics on the mechanical and rheological properties of poly(butylene terephthalate)/glass fiber composites. J. Appl. Polym. Sci.2010, 116, 3005-3012.

[17] Hassan, A.; Rahman, N.;Rosiyah, Y. Extrusion and injection-molding of glass fiber/MAPP/polypropylene: Effect of coupling agent on DSC, DMA, and mechanical properties. J. Reinf. Plast. Compos. 2011, 30, 1223-1232.

[18] Ozkoc, G.;Bayram, G.;Bayramli, E. Short glass fiber reinforced ABS and ABS/PA6 composites: Processing and characterization. Polym Compos. 2005, 26, 745-755.

[19] Thomason, J.; The influence of fiber length, diameter and concentration on the impact performance of long glass-fiber reinforced polyamide 6,6. Composites Part A. 2009, 40, 114-124.

[20] Jiang, H.; Pascal Kamdem, D.; Bezubic, B.; Ruede, P. Mechanical properties of poly(vinyl chloride)/wood flour/glass fiber hybrid composites. J Vinyl Addit Technol, 2003, 9, 138145.

[21] Rudolph D.; Deanin, Gerardo R. Glass-fiber-reinforced poly(butylene terephthalate) structural foam, In: ANTEC 83: plasticsengineering today for tomorrow’s world, Chicago, USA, May 2-5, 1983.

[22] Tungjitpornkull, N.;Chaochanchaikul, K.;Sombatsompop, N.Mechanical Characterization of E-Chopped Strand Glass Fiber Reinforced Wood/PVC Composites. J. Thermoplast. Compos. Mater. 2007, 20, 535-550.

[23] Zhao, R.; Huang, J.; Sun, B.;Dia, G. Study of the mechanical properties of Mica-filled polypropylene-based GMT composite. J. Appl. Polym. Sci. 2001, 82, 2719-2728.

[24] Raj, R.;Kokta, B.;Daneault, C. Comparative study on the effect of aging on mechanical properties of LLDPE-glass fiber, mica, and wood fiber composites. J. Appl. Polym. 1990, 40, 645-655.

[25] Canova, L.; Ferguson, L.; Parrinello, L.; Subramanian, R. Giles, H. F.; Jr. Effect of Combinations of Fiber Glass and Mica on the Physical Properties and Dimensional Stability of Injection Molded Polypropylene Composites. Annual Technical Conference - ANTEC, Conference Proceedings, Toronto, Can, Apr. 27-May 2, 1997.

[26] Jiang, H.; Kamdem, D. Development of poly(vinyl chloride)/wood composites. A literature review. J. Vinyl Add. Tech. 2004, 10, 59-69. 
[27] Pytel, A.; Singer, F.Strength of Materials. Fourthedition. 1987.

[28] Lu, H.; Purushothama, S.; Hyatt J, Pan, W.; Riley, J.; Lloyd, W.; Flynn J.; Gill P. Co-firing high-sulfur with refuse-derived fuel. Thermochim. Acta. 1996, 284, 161-171.

[29] Khoshnoud, P.;Gunashekar, S.; Jamel, M.M.; Abu-Zahra, N. Comparative analysis of rigid PVC foam reinforced with class C and class F fly ash.J. Min. Mat. Char. \& Eng 2014, 2, 554-565.

[30] Qiao, J.;Amirkhiz,i A.;Schaaf, K.;Nasser S.. Dynamic Mechanical Analysis of Fly Ash Filled Polyurea Elastomer. J. Eng. Mater. Technol. 2010, 133, 011016-011016-7.

[31] Matuana, L.; Park, C.;Balatinecz, J. Cell morphology and property relationships of microcellular foamed PVC/wood-fiber composites. PolymEng Sci. 2004, 38, 1862-1872.

[32] Luong, D.;Pinisetty, D.; Gupta, N. Compressive properties of closed-cell polyvinyl chloride foams at low and high strain rates: Experimental investigation and critical review of state of the art. Composites Part B-Eng. 2013, 44, 403-416.

[33] Collocaa, M.; Dorogokupetsa, G.; Gupta, N.; Porfiri M. Mechanical properties and failure mechanisms of closed-cell PVC foams. Int. J. Crashworthines. 2012, 17, 327-336.

[34] Xanthos M. Functional Fillers for Plastics. 2nd ed. 2010, p.14-16

[35] Edited by Thomas, S; Joseph, K; Malhotra, S; Goda,K; Sreekala, M. Polymer Composites, 2012, p. 673-696. 


\section{APPENDIX}

\section{LIST OF PUBLICATIONS AND SUBMISSIONS}

1. Enhancement of Dimensional Stability of Rigid PVC Foams using E-Glass Fibers Murtatha M. Jamel, ParisaKhoshnoud, SubhashiniGunashekar, Nidal Abu-Zahra Journal of Minerals and Materials Characterization and Engineering, submitted on $10 / 26 / 2014$

2. Mechanical Properties and Dimensional Stability of Rigid PVC Foam Composites Filled with High Aspect Ratio Phlogopite Mica

Murtatha M. Jamel, ParisaKhoshnoud, SubhashiniGunashekar, Nidal Abu-Zahra Journal of Polymers, submitted on 11/14/14

3. Effect of E-Glass Fibers and Phlogopite Mica on the Mechanical Properties and Dimensional Stability of Rigid PVC Foams

Murtatha M. Jamel, Parisa Technology and Engineering, submitted on12/5/2014

4. Characterization of Rigid PVC Foam Composites Reinforced with Fly Ash ParisaKhoshnoud, Murtatha M. Jamel, SubhashiniGunashekar, Nidal Abu-Zahra Journal of Polymers and the Environment, submitted on 9/16/2014

5. Comparative Analysis of Rigid PVC Foam Reinforced with Class C and Class F Fly Ash.

ParisaKhoshnoud, SubhashiniGunashekar, Murtatha M. Jamel, Nidal Abu-Zahra Journal of Minerals and Materials Characterization and Engineering, 2014, 2, 554565.

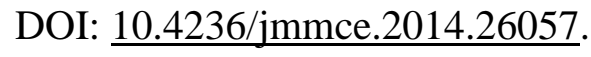

